\title{
THE EFFICIENT QUEUE AND THE CASE AGAINST SURGE PRICING
}

\author{
Ramsi A. Woodcock ${ }^{*}$
}

\begin{abstract}
Surge pricing — using data and algorithms to raise prices in response to unexpected increases in demand - has spread across the economy in recent years, from Amazon, to Disney World, to commuter highways, not to mention Uber, which is infamous for surge pricing rides. Companies claim that surge pricing equilibrates supply and demand, but that is impossible, at least in the short run when demand unexpectedly outstrips supply. What surge pricing really does is to ration existing supplies based on ability to pay. That is both distributively unjust and potentially inefficient. It is also anticompetitive in the sense that it reduces the power of the competitive pricing that prevails before a surge in demand to carry over into the surge period. As such, surge pricing is similar in effect to price fixing, which also prevents competitive pricing from carrying over into periods during which firms as a group have obtained power to raise prices. Courts should therefore rule surge pricing per se illegal under the antitrust laws, just as they do price fixing today.
\end{abstract}

\footnotetext{
* Assistant Professor, University of Kentucky Rosenberg College of Law, Secondary Appointment, Department of Management, University of Kentucky Gatton College of Business and Economics. Harry First, Niklas Dürr, and participants at the 13th Academic Society for Competition Law Conference at New York University School of Law, a May 2018 meeting of the Mannheim Competition Policy Forum at the University of Mannheim, and a May 2018 CMA Academy session at the United Kingdom's Competition and Markets Authority, provided helpful comments. This research was supported in part by a grant from the John S. and James L. Knight Foundation.
} 


\section{Table of Contents}

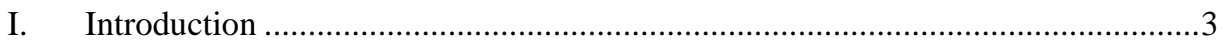

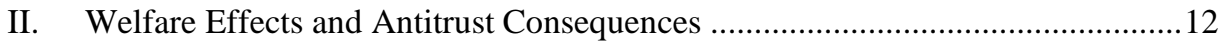

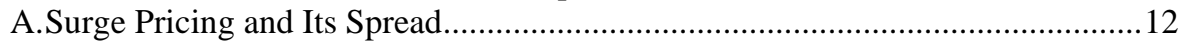

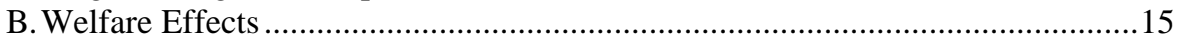

C. Antitrust Liability .................................................................................... 23

1. The Existence of Anticompetitive Conduct and Monopoly Power.................23

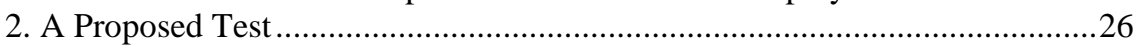

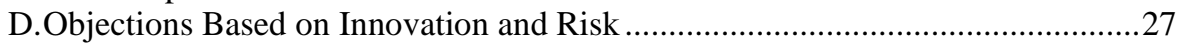

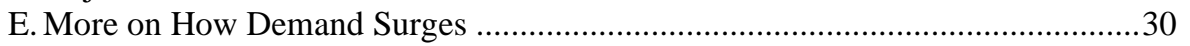

F. Distinguishing Surge Pricing from Dynamic Pricing .................................... 35

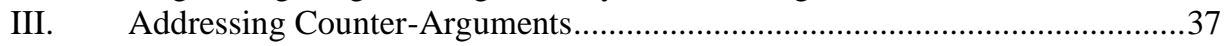

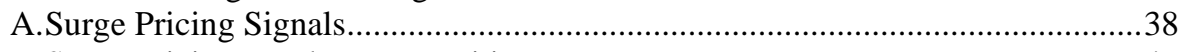

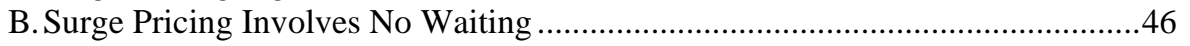

C. Surge Pricing Allocates ...............................................................................52

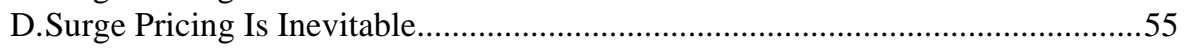

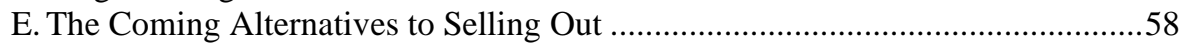

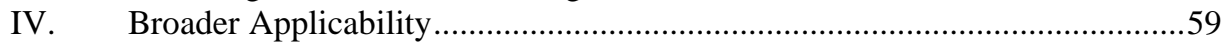

A.Resale, Securities and Commodities Trading, and Price Gouging ....................59

1. Resale and Securities and Commodities Trading ....................................59

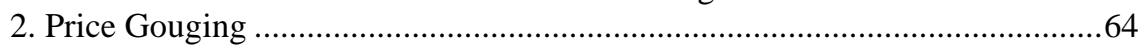

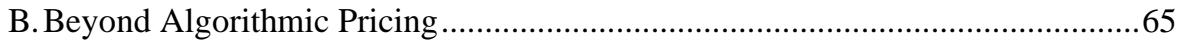

1. Toward a Blanket Ban on All Surge Pricing, Including Non-Algorithmic

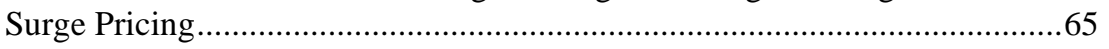

2. Implications for Theories of Securities and Commodities Trading ................66

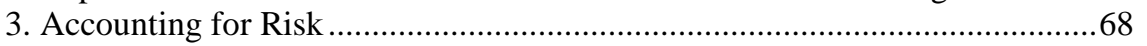

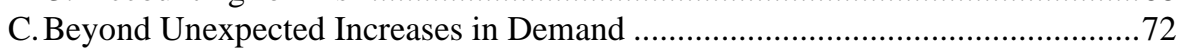

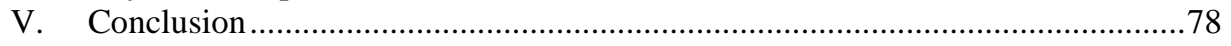




\section{INTRODUCTION}

It was on New Year's Day 2012 that Americans first became aware of the spread of algorithmic pricing, as Uber charged revelers many times the regular fare for rides home, triggering a backlash on social media. ${ }^{1}$ The $\$ 27$ ride that went for $\$ 135$ was not some computer glitch, it turned out, but, as Uber explained, the result of a policy designed to equilibrate supply and demand. ${ }^{2}$ When demand for rides surges unexpectedly, argued Uber, there may be too few Uber drivers in the area to satisfy it. ${ }^{3}$ To coax them into entering the market, Uber must offer drivers more money, and to do that Uber must charge higher prices to riders. ${ }^{4}$ That is ultimately good for riders, argued Uber, because it ensures that enough drivers will enter the area to get everyone a ride home, and fast. ${ }^{5}$

The trouble with this story, researchers later found, was that the high prices Uber charges in response to unexpected surges in demand often fail to induce more drivers to enter the market, but Uber still charges the higher prices to riders anyway. ${ }^{6}$ Herein lies an important lesson about algorithmic pricing: it allows prices to change much more quickly than productionwhich for the most part remains a brick-and-mortar concept-can react. When Uber experiences a surge in demand, the company's pricing algorithms respond immediately to raise prices for rides that are already in the area, long before additional drivers are able to enter the area, if they enter at all.

\footnotetext{
${ }^{1}$ See Nick Bilton, Disruptions: Taxi Supply and Demand, Priced by the Mile, BITS BLOG (Jan. 8, 2012), https://bits.blogs.nytimes.com/2012/01/08/disruptions-taxi-supply-anddemand-priced-by-the-mile/. An early version of this article was published, against the author's wishes, as Ramsi A. Woodcock, The Efficient Queue and the Case Against Dynamic Pricing, 105 IOWA L. REV. 1759 (2020). The present Article provides a much more coherent development of some of the ideas contained in that early version. Because that early version was no more than an early draft of the present Article, the present Article does not cite to the early draft. (However, the present Article does cite to several intervening published works by this author that themselves do cite to that early version.) Readers wishing to trace the genealogy of the ideas herein are encouraged to consult the draft directly and compare it with the present Article.

2 See Bilton, supra note 1; Mike Murphy, Uber Got Two Economics PhDs to Explain How Supply and Demand Works, QUARTZ (Sep. 17, 2015), https://qz.com/505031/uber-got-twoeconomics-phds-to-explain-how-supply-and-demand-works/.

${ }^{3}$ See Murphy, supra note 2.

${ }^{4}$ See id.

${ }^{5}$ See id.

${ }^{6}$ See Le Chen et al., Peeking Beneath the Hood of Uber, Proceedings of the 2015 ACM Conference on Internet Measurement 495, 506-7 (2015).
} 
The mismatch between the speed of price and the speed of production in the information age is leading to harm not just to Uber riders but to consumers across the economy, as surge pricing - the use of algorithms to accelerate the process of raising prices in response to unexpected surges in demand - has spread far beyond rideshare to everything from Disney World tickets to highway tolls. ${ }^{7}$ It should also lead to antitrust liability. For efforts to deepen the mismatch between price and output speeds are fundamentally anticompetitive.

Surges in demand create shortages, because firms cannot increase output instantaneously, and shortages create market power, because shortages prevent buyers from finding alternative supplies if they do not like the prices charged by the firms with which they normally do business. But when the speed of price roughly equals the speed of production, firms are unable to exploit this shortage-based power. By the time they are able to raise prices, their competitors have increased output to satisfy the excess demand, and the shortage and associated power over price are gone. Thanks to the inability of price to adjust faster than output, the competitive prices of the pre-shortage period govern the shortage period as well. Surge pricing is anticompetitive because, by accelerating the speed of price relative to that of production, surge pricing prevents competitive pricing from carrying over from the pre-shortage period into the shortage period, weakening the effects of competition and enabling the firm to raise prices and harm consumers.

An unexpected surge in demand creates a shortage because firms choose the number of units they will produce to match demand at the market price. When the surge hits, many more prospective buyers show up willing to buy at the market price than the firm has units available to sell to them. It would be great if the solution were for the firm simply to produce more units to satisfy the excess demand, as Uber hopes will happen when the company raises rideshare prices to draw more drivers into the area. ${ }^{8} \mathrm{But}$ production takes time: minutes in the case of rides on New Year's Eve, weeks in the case of a pandemic-induced run on webcams that must be manufactured in China and then shipped in containers across the deep blue

7 See Disney Discovers Peak Pricing, ECONOMIST (Feb. 29, 2016), https://www.economist.com/free-exchange/2016/02/29/disney-discovers-peak-pricing; Bart Jansen, 'Dynamic Tolls': How Highways Can Charge \$40 for Driving Just 10 Miles, USA TODAY, $\quad$ https://www.usatoday.com/story/news/2017/12/07/states-governmentsincreasingly-turn-tolls-manage-highway-traffic-jams/930900001/ (last visited May 1, 2020).

${ }^{8}$ See Murphy, supra note 2. 
sea. ${ }^{9}$ The shortage will therefore not disappear as soon as it strikes, but rather endure in the short term until additional output makes its way to market.

During the shortage period, the firm will have the power to raise prices because it is the ability of supply to increase in response to a surge in demand that normally puts downward pressure on prices. ${ }^{10}$ In a competitive market, a firm cannot raise prices because competitors have output handy that they can sell, at a lower price, to the firm's customers. But when a firm faces an unexpected surge in demand, competition halts temporarily, because firms cannot adjust output instantaneously. Until competitors can ramp up production, firms do not need to worry that if they raise prices competitors will have output handy that they can sell at lower prices to the firm's customers.

Surge pricing is anticompetitive because it undermines a technological status quo that once limited the ability of firms to exploit the market power created by unexpected surges in demand. Because firms once could not recall advertisements that had been printed and distributed, reprint all their menus, or cross the prices off the sides of all their packaging much more quickly than they could ramp up their output in response to an unexpected surge in demand, firms were stuck continuing to charge competitive prices even after a demand surge had given them the power to raise prices. ${ }^{11}$ Indeed, firms often did not even know that they faced a demand surge until it was all over, as they lacked up-to-date information on how quickly their products were selling out in far-flung retail outposts. ${ }^{12}$ The algorithms that enable surge pricing eliminate these obstacles, and the resulting price rigidity, allowing firms to jack up prices as soon as demand spikes. In this way, the tendency of competitive pricing to carry over from the pre-surge period into the surge period is made to disappear. ${ }^{13}$

To be sure, surge pricing is not directly anticompetitive in the way of

\footnotetext{
${ }^{9}$ See Le Chen et al., Peeking Beneath the Hood of Uber, Proceedings of the 2015 ACM Conference on Internet Measurement 495, 506 (2015); Rachel Lerman, The Hunt for a Work-from-Home Webcam: A Story of Broken Supply Chains, 'Sold-Out' Messages and Refreshing Online Carts, WASH. POST (Mar. 21, 2020), https://www.washingtonpost.com/technology/2020/05/21/webcam-backorder-coronaviruspandemic/.

${ }^{10}$ See David J. Teece \& Mary Coleman, The Meaning of Monopoly: Antitrust Analysis in High-Technology Industries, 43 ANTITRUST BULL. 801, 818 (1998).

11 See Alan Blinder et Al., Asking About Prices: A New Approach to UNDERSTANDING PRICE STICKINESS 226-53 (1998).

${ }^{12}$ See Emek Basker, Raising the Barcode Scanner: Technology and Productivity in the Retail Sector, 4 AM. ECON. J. APPLIED ECON. 1, 2 (2012).

${ }^{13}$ See Chen et al., supra note 9, at 503-4.
} 
most practices prohibited by the antitrust laws. A firm's decision to stop selling an essential input to a competitor, for example, directly increases the firm's power to raise prices by depriving the competitor of the ability to remain in the market, which is why such terminations can violate Section 2 of the Sherman Act. ${ }^{14}$ By contrast, surge pricing does not drive competitors from markets or otherwise disrupt supply, and therefore does not directly create power over price. The unexpected surge in demand and coincident output shortage create that power instead. ${ }^{15}$ But surge pricing does prevent the relatively competitive prices of the pre-shortage period from carrying over into the shortage period, which is to say that it limits the effects of competition and enables exercise of the market power created by an unexpected demand surge.

Antitrust treats action that magnifies the effects of an independent collapse in competition as anticompetitive conduct. One example is antitrust's per se rule against price fixing. ${ }^{16}$ Price fixing can directly harm competition. If a group of firms engaged in competition with each other agree to fix a high price, the agreement itself may be said to eliminate competition in the market. For as a result of the agreement the parties will no longer behave like competitors. But often firms that agreed to fix prices are not initially in genuine competition with each other, but instead are already colluding tacitly. ${ }^{17}$ The firms use their price-fixing agreement only to make explicit the terms of their pre-existing cooperation. ${ }^{18}$ In this case, price fixing cannot be said directly to eliminate competition. Instead, like surge pricing, price fixing in this context can be said only to exploit a preexisting competitive vacuum, one that, thanks to antitrust immunity for tacit collusion, is, like the power created by shortage, not itself a violation of the antitrust laws. ${ }^{19}$

Firms might, for example, tacitly collude to charge a price of $\$ 10$ for their goods, even though the power created by their collusive behavior would allow them profitably to charge a price of $\$ 15$ instead. Entering into an explicit agreement to charge $\$ 15$ enables them to choose the highest price made possible by their preexisting collusive behavior, but does not involve any additional direct harm to competition, since they are already

\footnotetext{
14 See Herbert Hovenkamp, Federal Antitrust Policy, the Law of Competition AND ITS PRACTICE 382-87 (6th ed. 2020).

15 See Teece \& Coleman, supra note 10 , at 818 .

${ }^{16}$ See HoVENKAMP, supra note 14, at 330-31.

${ }^{17}$ See Richard A PoSNER, ANTITRUST LAW 52-53 (2d ed. 2001).

${ }^{18}$ See HovenKamP, supra note 14, at 202.

${ }^{19}$ See id. at 210-13.
} 
colluding tacitly to raise prices. ${ }^{20}$ Like surge pricing, the agreement serves only to enable the parties more fully to exploit power created by another source: in this case preexisting, and entirely legal, tacit collusion. ${ }^{21}$ The courts would nevertheless consider this example of price fixing to be anticompetitive conduct, and indeed would prohibit it, just as courts should consider surge pricing to be anticompetitive conduct as well, even though surge pricing is not directly anticompetitive. ${ }^{22}$

The antitrust laws do not usually prohibit anticompetitive conduct per se, but instead usually prohibit anticompetitive conduct only when undertaken by firms having substantial market power, which may not be the case in every instance of surge pricing. ${ }^{23}$ The courts recognize an exception, however, where the conduct almost always harms consumers, and surge pricing always harms consumers, which is why antitrust should treat surge pricing not just as anticompetitive conduct but as conduct that is illegal per se. ${ }^{24}$ Surge pricing always harms consumers because, the special case of ruinous competition aside, firms choose their prices to cover their costs, inclusive of the return that investors demand for having invested in the firm. It follows that when a firm raises its prices in response to an unexpected demand surge, the firm raises its prices above its costs, and so redistributes wealth from consumers to the firm unnecessarily. But unnecessarily redistributive pricing is the very definition of consumer harm in antitrust. $^{25}$

Surge pricers such as Uber argue that the higher prices made possible by surge pricing are necessary to call forth additional output to satisfy the excess demand. ${ }^{26}$ If that were the case, then the higher prices could not be said to harm consumers, for they would no longer be a mechanism for redistributing wealth away from consumers, but instead necessary to ensure that consumers gain access to a product that they wish to buy. ${ }^{27}$ There is a

${ }^{20}$ See POSNER, supra note 17 , at 52.

21 See id. at 55.

${ }^{22}$ See United States v. Socony-Vacuum Oil Co., 310 U.S. 150, 223 (1940) ("Under the Sherman Act a combination formed for the purpose and with the effect of raising, depressing, fixing, pegging, or stabilizing the price of a commodity in interstate or foreign commerce is illegal per se.").

${ }^{23}$ See Timothy J. Muris, The New Rule of Reason, 57 ANTITRUST L.J. 859, 861 (1988).

${ }^{24}$ See Broadcast Music, Inc. v. Columbia Broadcasting System, Inc., 441 U.S. 1, 19-20 (1979).

25 See John B. Kirkwood \& Robert H. Lande, The Fundamental Goal of Antitrust: Protecting Consumers, Not Increasing Efficiency, 84 NOTRE DAME L. REV. 191, 192 (2008).

${ }^{26}$ See Murphy, supra note 2.

${ }^{27}$ See John B. Kirkwood, Market Power and Antitrust Enforcement, 98 B.U. L. REV. 1169, 
naïve version of this argument that holds that no matter how quickly surge pricing kicks into gear, the higher prices instantaneously call forth additional production. ${ }^{28}$ That of course cannot be the case until the information age becomes the teleportation age and matter can be beamed from place to place in the same way that price information is beamed from place to place today. Until then, price will outrun production. ${ }^{29}$ Even in the case of Uber, in which the extra supply is literally on wheels and need only move from one neighborhood to another, production cannot, as already observed, adjust instantaneously to increases in price.

There is a second, more sophisticated version of the argument that higher prices are necessary to call forth additional supply, one that acknowledges that higher prices do not trigger an immediate increase in supply, but which argues that higher prices nevertheless do act as a signal to other firms that it would be profitable to produce higher-cost output in the short term. ${ }^{30}$ According to this argument, although higher prices for existing, low-cost inventory are frankly redistributive, they are nevertheless a necessary evil, because without them the market will adjust more slowly to the spike in demand. ${ }^{31}$ When drivers relaxing at home see that other drivers are making a killing thanks to surge pricing, the argument goes, they will eventually, though not instantaneously, get up and drive over to the surge area to earn some extra cash, eliminating the shortage before too long. 32

The trouble with this signaling argument is that the alternative to charging high prices - just letting goods sell out at current prices-sends just as clear a signal that entry into a market would be profitable, and may even lead firms to satisfy the excess demand at lower cost. ${ }^{33}$ The high price charged by surge pricing of a particular good is a rough signal of the maximum price that consumers are willing to pay for the good, because surge pricing picks prices to maximize profits. By contrast, the price

1176 (2018).

${ }^{28}$ See Pierre Lemieux, Toilet Paper: Increasing Marginal Cost, ECONLIB (Apr. 13, 2020), https://www.econlib.org/toilet-paper-increasing-marginal-cost/. [https://perma.cc/7QD9EMPB].

${ }^{29}$ See Anton Zeilinger, Quantum Teleportation, 282 SCI. AM., Apr. 2000, at 50, 50.

${ }^{30}$ See Jonathan Hall et al., The Effects of Uber's Surge Pricing: A Case Study, THE UNIVERSITY OF CHICAGO BOOTH SCHOOL OF BUSINESS 1 (2015).

${ }^{31}$ See id. at $1-5$.

${ }^{32}$ See Murphy, supra note 2.

${ }_{33}$ See Ramsi A. Woodcock, The Economics of Shortages, LAW \& Pol. ECON. Blog (Jun. 2, 2020), https://lpeblog.org/2020/06/02/the-economics-of-shortages/; Ramsi A. Woodcock, The Hidden Shortages of the Market Economy, LAW \& POL. ECON. BLOG (Jun. 3, 2020), https://lpeblog.org/2020/06/03/the-hidden-shortages-of-the-market-economy/. 
charged by the firm that lets the good sell out at the pre-surge price is a rough measure of the cost of producing the good, because the pre-surge price is set in a relatively competitive market and competition tends to drive prices to costs. Sellers that observe that the price of a good is surging, and therefore reflects consumers' maximum willingness to pay for the good, learn that they likely would be able to enter the market and sell at a slightly lower price. Sellers that observe that a good has sold out at a competitive, and therefore cost-determined, price learn that they likely would be able to enter the market and sell at a slightly higher price. The signal to enter the market is the same, but because in the case of selling out at the pre-surge price the price information conveyed is anchored to the cost of producing the good, selling out is more likely to attract the lowest-cost producers to the market first, ensuring that excess demand is satisfied in the most efficient way. By contrast, pricing at high levels reflective of consumers' maximum willingness to pay will not screen out high-cost producers.

In other words, if Uber's surge prices are high enough, drivers are just as likely to walk off a temp job as to get off the couch in order to sell some rides, even though society is better off if the excess demand is satisfied by drivers who would otherwise be doing nothing at home than by those working other valuable jobs. By contrast, notice that there are plenty of unfilled ride requests, and the opportunity to earn a modest premium, would get drivers off their couches, but likely would not induce them to walk off other jobs.

A surge pricer might also argue that, while surge pricing may not be necessary to equilibrate supply and demand, it is necessary to ensure that those who place the highest value on a shortage good are the ones to buy and enjoy it. ${ }^{34}$ If that were true, then the higher prices could not be said to harm consumers, because they would be necessary to ensure that those who value the good the most get access to it. The problem faced by the firm during a surge in demand is really a problem of rationing. If the firm allows the good to sell out at the current price, then the firm rations based on antecedence - the rule of first come, first served. If the firm raises price, then the firm rations based on willingness to pay, pricing those who are not willing to pay out of the market and delivering the good to those who are. Economists tend to assume that willingness to pay is a good proxy for the value a consumer places on an item, meaning that those who are willing to pay more actually get more pleasure out of the good than those who are

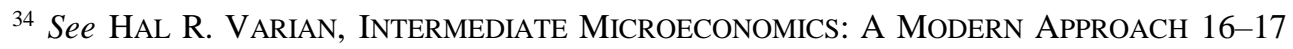
(7th ed. 2006).
} 
only willing to pay less. ${ }^{35}$ But the assumption is wrong, as economists themselves are often the first to admit. ${ }^{36}$ We all know that the wealthy, having more money than the poor, place less value on their cash than do the poor, reducing the usefulness of the sums that the rich are willing to pay for any particular good as a measure of the value the rich actually place on the good. ${ }^{37}$ It follows that willingness to pay is an imperfect proxy for value, and that there is no basis for supposing that it is any less imperfect of a proxy than is antecedence. Those who place a higher value on a good are probably more likely to line up for it before those who place a lower value on the good. But, like willingness to pay, the correspondence between antecedence and value is inexact. Some get lucky, and others have an advantage in getting to the head of the line, such as being fleeter of foot or having a faster computer, that may have nothing to do with the value they place on the good. True, the wealthy can in effect convert antecedencebased rationing into high-price-based rationing by buying their way to the head of the line. ${ }^{38}$ But that does not give willingness to pay an advantage as a proxy for value. For often those who amass great wealth do so by being first to exploit an opportunity, effectively converting rationing with high prices into rationing based on antecedence. ${ }^{39}$ As a proxy for value, rationing with high prices has no obvious advantage over rationing with antecedence.

That was not, however, always true. Before the information age, rationing with antecedence had an added cost relative to rationing with high prices: waiting in physical lines was a waste of time. ${ }^{40}$ The Internet has almost completely eliminated that cost. Today, any firm wishing to maintain current prices in the face of a demand surge does not need to make customers actually wait in order to ration based on antecedence. If the firm sells online, customers can log into the firm's website and either buy or receive a "sold out" notice instantaneously. At worst, the cost is the time required to select an item and click through to the checkout screen only to

35 See Eugene Silberberg, The Structure of Economics: A Mathematical ANALYSIS 396-405 (2d ed. 1990).

${ }^{36}$ See id.

${ }^{37}$ See Alfred Marshall, PRINCIPLeS OF ECONOMICS 80-81 (8th ed. 1920).

${ }^{38}$ See Deacon Robert T. \& Sonstelie Jon, The Welfare Costs of Rationing by Waiting, 27 ECON. INQUIRY 179, 179 (1989); N. Gregory Mankiw, I Paid \$2,500 for a 'Hamilton' Ticket. I'm Happy About It., N.Y. TIMES (Oct. 21, 2016), https://www.nytimes.com/2016/10/23/upshot/i-paid-2500-for-a-hamilton-ticket-im-happyabout-it.html.

39 See F. M Scherer \& David Ross, Industrial Market Structure and Economic PERFORMANCE 626-30 (3d ed. 1990).

${ }^{40}$ See Robert T. Deacon \& Jon Sonstelie, Rationing by Waiting and the Value of Time: Results from a Natural Experiment, 93 J. POL. ECON. 627, 627-28 (1985). 
find that someone else has clicked "submit" a split-second faster. If the firm sells in brick-and-mortar stores, it can implement an online reservation system, as many big retailers have already done under the "in-store pickup" moniker. ${ }^{41}$ The queue is now efficient.

Surge pricing belongs to a broader category of algorithmic pricing practices, known as dynamic pricing, that have in common the goal of adjusting price in response to unexpected changes in demand. ${ }^{42}$ Surge pricing reacts to unexpected increases in demand. Other forms of dynamic pricing react to unexpected decreases in demand. Somewhat confusingly, these other forms of dynamic pricing may nevertheless increase prices, just as surge pricing does. These other forms of dynamic pricing do not necessarily violate the antitrust laws, however, because, unlike price increases that respond to demand surges, price increases that respond to demand shortfalls do not always harm consumers. If a firm must recoup high up-front costs, for example, the firm may need to raise prices in response to lower sales volumes in order to extract more revenue per unit and thereby to continue to cover those costs. By contrast, what makes surge pricing always harmful to consumers is that a surge in demand does not reduce sales volumes, and so the firm could cover its costs without jacking up its prices, rendering any price increase purely a matter of redistribution of wealth from consumers to the firm.

The fact that other forms of dynamic pricing may lead to price increases that do not harm consumers suggests that a per se rule against surge pricing might be difficult to enforce, as it might be difficult to distinguish between good and bad price increases. That is unlikely to be true, however, because courts can reliably identify surge pricing using four elements, all of which can be established through discovery of a defendant's pricing and inventory systems. A firm that, (1) uses algorithms to set its prices, (2) experiences a surge in demand, and (3) increases its prices in response to that surge, (4) faster than the firm increases its supply, must be engaged in surge pricing. Other forms of dynamic pricing respond to declines in demand, rather than surges, and so would be screened out by this test.

Proof of the existence of these elements should also be sufficient to make out a claim for per se liability for surge pricing under Section 2 of the

41 See Retailer's Shortcut From Desktop to Store - The New York Times, https://www.nytimes.com/2007/09/24/technology/24ecom.html?searchResultPosition=5 (last visited Sep. 20, 2020).

42 See Tim Walker, How Much ...? The Rise of Dynamic and Personalised Pricing, GUARDIAN, http:/www.theguardian.com/global/2017/nov/20/dynamic-personalisedpricing (last visited May 30, 2018). 
Sherman Act. ${ }^{43}$ The first element - the requirement that the pricing be algorithmic - establishes the existence of the anticompetitive conduct that the firm increased its pricing speed relative to its production speed and in this way reduced the period during which competitive pricing persists into the demand surge. Existence of the other three elements establishes that the firm necessarily harmed consumers by increasing price during the shortage period incident to a surge in demand. Liability should follow immediately under Section 2, because Section 2 prohibits anticompetitive and consumerharmful conduct by individual firms. ${ }^{44}$ This would be the first per se prohibition to be recognized under Section 2, as all existing Section 2 prohibitions require proof of market power. ${ }^{45}$ But new technology demands new law.

Part II argues that surge pricing is anticompetitive, harmful to consumers, and therefore should be banned under the antitrust laws. Part III refutes the objections that surge pricing is the best way to stimulate supply or to allocate scarce resources. Part IV considers the implications of this analysis for securities and commodities trading, the theory of price gouging, surge pricing that does not use algorithms, and the sale of naturally scarce, unimproved resources.

\section{WeLFARE EFFECTS AND ANTITRUST CONSEQUENCES}

\section{A. Surge Pricing and Its Spread}

Some information age pricing practices, such as personalized pricing, remain but a twinkle in the eye of tech-savvy CFOs. ${ }^{46}$ But not surge pricing, which is far from being a unique contribution of Uber to information age dystopia. Surge pricing has, in fact, spread with remarkable speed across the business world over the past decade, and its roots stretch back further to the dawn of the computer age. American Airlines pioneered surge pricing in the 1970s, programming mainframe computers to implement it in crude form: charging higher prices for seats on full planes

\footnotetext{
43 15 U.S.C. $\$ 2$ (2018).

44 See Andrew I. Gavil et Al., Antitrust law in Perspective: Cases, Concepts, and PROBLEMS IN COMPETITION POLICY 437 (3d ed. 2017).

45 See Martin J. Adelman \& Ernie L. Brooks, The Integrity of the Administrative Process, Sherman Section 2 and Per Se Rules - Lessons of Fraud on the Patent Office, 19 WAYNE L. REV. 1, 11 (1972).

46 See Ariel EzRachi \& Maurice E Stucke, Virtual Competition: The Promise and PERILS OF THE ALGORITHM-DRIVEN ECONOMY 89-100 (2016) (observing that personalized pricing is "unlikely in many markets in the near future").
} 
than for those on empty planes. ${ }^{47}$ From there, surge pricing spread to the other airlines and then to the hospitality industry in the 1980s, which used it to charge higher rates for rooms in full hotels than for those in empty hotels. ${ }^{48}$ Along the way, it grew more sophisticated and acquired the names "yield management" and "revenue management."49 Before the Internet, surge pricing appears to have been limited to travel, hospitality, parcel shipping, and auto sales, perhaps because sellers in these industries were some of the few to enjoy the scale necessary to invest in the sort of dedicated electronic communications networks required to manage surge pricing before the Internet. ${ }^{50}$

The advent of the Internet has eliminated the need to create proprietary electronic communications networks in order to run surge pricing operations, and has consequently made surge pricing available to virtually every business. ${ }^{51}$ Apartment rental companies, which lacked the scale of the hotel chains required to justify investment in a proprietary electronic network and so did not engage in surge pricing before the Internet now charge surge prices for apartment leases. They use third-party pricing companies like Yieldstar and LRO to manage their prices. ${ }^{52}$ Before the pandemic hit, Broadway shows were crediting surge pricing of theater tickets with a remarkable increase in profitability after years of hard times, as retail prices for Hamilton tickets spiked above $\$ 1,000$ during peak periods of demand. ${ }^{53}$ Indeed, much of the events industry, including pop

47 See Richard H. K VIETOR, CONTRIVED COMPETITION: REGUlation AND Deregulation In AMERICA 63-64, 69-72 (1996); Robert G. Cross et al., Milestones in the Application of Analytical Pricing and Revenue Management, 10 J. REVENUE \& PRICING MGMT. 8, 9-11 (2011).

${ }^{48}$ See Cross et al., supra note 47 , at 11-12.

49 See id. at 10-11.

${ }^{50}$ See id. at $12-15$.

51 See Dax Cross, A History of Revenue Management and the Advent of Next-Generation RM, 15 J. REVENUE \& PRICING MGMT. 293, 293-94 (2016).

52 See NowshabA AHMEd ET AL., APPliCATIONS OF REVEnUE MANAGEMENT IN APARTMENT RENTAL INDUSTRY 17-22, 30, available at https://personal.utdallas.edu/ metin/Or6377/Reports/

RMforApartments.pdf [https://perma.cc/25A9-RVML].

${ }^{3}$ See Patrick Healy, New Pricing Strategy Makes the Most of Hot Broadway Tickets, N.Y. TIMES (Nov. 24, 2011), http://www.nytimes.com/2011/11/25/arts/new-pricing-strategymakes-the-most-of-hot-broadway-tickets.html; Michael Paulson, High Ticket Prices Are Fueling a Broadway Boom, N.Y. TIMES (May 23, 2017), https://www.nytimes.com/2017/05/23/theater/high-ticket-prices-are-fueling-a-broadwayboom.html; Gordon Cox, 'Hamilton' Ticket Prices Hit New High With \$1,150 Premium, VARIETY (Dec. 26, 2017), http://variety.com/2017/legit/news/hamilton-ticket-prices$1202648756 /$. Broadway was pushed into surge pricing in part by the rise of automated 
concerts, Ticketmaster, and sports, has embraced the practice. ${ }^{54}$ Even Disney World has gotten into the act. ${ }^{55}$

Most Americans are likely to have paid surge prices not to these companies, however, but to Amazon, which is a global leader in the practice, and indeed markets its surge pricing services to the third-party sellers that use its platform. ${ }^{56}$ During the first months of the pandemic, Americans noticed that whereas toilet paper or hand sanitizer tended to be sold out at local brick-and-mortar stores, these items were not sold out on Amazon, only more expensive, which is precisely what one would expect to

ticket scalpers, which bought up tickets and then implemented their own surge pricing schemes in resale markets. See James B. Stewart, Broadway Tickets, for the Price of an Economics Lesson, N.Y. TIMES (June 8, 2017), https://www.nytimes.com/2017/06/08/business/broadway-theater-ticket-prices.html [https://perma.cc/WA6C-B3SA ]; see also Robert J. McFadden, Note, The BOTS Act: A Small Step for Fankind When a Giant Leap Is Needed, 55 WASHBURN L.J. 427, 427-29 (2016). Whether the show or the scalper does it, consumers suffer, as we shall see in this Part. Congress has responded to scalping with legislation, but it is not clear why scalpers should be sanctioned but original sellers should not when they engage in the same practice. See id. at 428-29.

${ }^{54}$ See Steve Knopper \& Steve Knopper, Taylor Swift's Ticket Strategy: Brilliant Business or Slowing Demand?, ROLLING STONE (Apr. 9, 2018), https://www.rollingstone.com/music/music-news/taylor-swifts-ticket-strategy-brilliantbusiness-or-slowing-demand-630218/ ("Superstars like Swift are increasingly using 'dynamic pricing' that shifts ticket prices constantly like airline seats."); How Are Ticket Prices and Fees Determined?, TICKETMASTER, https://help.ticketmaster.com/s/article/How-are-ticket-prices-and-fees-determined (last visited May 1, 2020) ("In some instances, events on our platform may have tickets that are 'market-priced,' so ticket and fee prices may adjust over time based on demand. This is similar to how airline tickets and hotel rooms are sold and is commonly referred to as 'Dynamic Pricing.'”); Stephen L. Shapiro \& Joris Drayer, A New Age of Demand-Based Pricing: An Examination of Dynamic Ticket Pricing and Secondary Market Prices in Major League Baseball, 26 J. SPORT MGMT. 532, 533-35 (2012).

${ }_{55}^{5}$ See Disney Discovers Peak Pricing, supra note 7.

56 See Kaye, supra note 10 (discussing Walmart's response to Amazon's changes in pricing); Bill Snyder, Report Analyzes Amazon's Dynamic Pricing Strategy, CIO (Jan. 16, 2015, 6:15 $\quad$ AM), https://www.cio.com/article/ 2870961/report-analyzes-amazons-dynamic-pricing-strategy.html [https://perma.cc/Q2YJE2P4]; see also Kathy Kristof, How Amazon Uses "Surge Pricing," Just Like Uber, CBS News (last updated Jul. 24, 2017, 10:08 AM), https://www.cbsnews.com/news/amazonsurge-pricing-are-you-getting-ripped-off-small-business [https://perma.cc/R8Y6-T2DX]; Wallop, supra note 9; Ankitha Nagaraj, Shipping From China To Amazon FBA Everything You Need to Know, SEllerAPP (Jan. 6, 2017), https://www.sellerapp.com/blog/how-to-get-your-shipments-from-china-to-amazon-fba/ [https://perma.cc/3N39-3NTA]. 
see from a surge pricing leader. ${ }^{57}$ Business has not, however, been alone in its embrace of surge pricing; governments have been turning to the practice as well. States and cities around the country have started applying surge pricing to highway tolls over the past two decades, and in 2019 New York City adopted a congestion pricing plan for downtown Manhattan that would allow the city to charge surge prices for access to city streets. ${ }^{58}$

\section{B. Welfare Effects}

The remarkable spread of surge pricing provides a lesson in the dangers of making basic economics a required course for undergraduates, because defenders of surge pricing tend to insist that surge pricing equilibrates supply and demand. ${ }^{59}$ They seem to have before their mind's eye the classic supply and demand diagram in Figure 1.

57 See Data Shows Amazon Raised Prices during Pandemic alongside Sellers Accused of Price Gouging, WFTS, https://www.abcactionnews.com/news/local-news/i-teaminvestigates/data-shows-amazon-raised-prices-during-pandemic-alongside-sellers-accusedof-price-gouging (last visited Jul. 29, 2021).

58 See Yingyan Lou et al., Optimal Dynamic Pricing Strategies for High-Occupancy/Toll Lanes, 19 Transportation Research PART C: EMERging TeChnOlogies 64, 64-65 (2011); Jansen, supra note 7 ("Forty jurisdictions nationwide have adopted tolls that fluctuate depending on traffic congestion since Southern California adopted the first one in 1995."); Vincent Barone, Congestion Pricing Passes, but without Key Details, AMNEWYORK, https://www.amny.com/transit/mta-congestion-pricing-cuomo-1-29209432/ (last visited May 1, 2020). For more on congestion pricing, see Winston Harrington et al., Overcoming Public Aversion to Congestion Pricing, 35 TRANSP. RES. PART A: POL'Y \& PRAC. 87, 87-89 (2001).

${ }^{59}$ See Bilton, supra note 1; Murphy, supra note 2. 


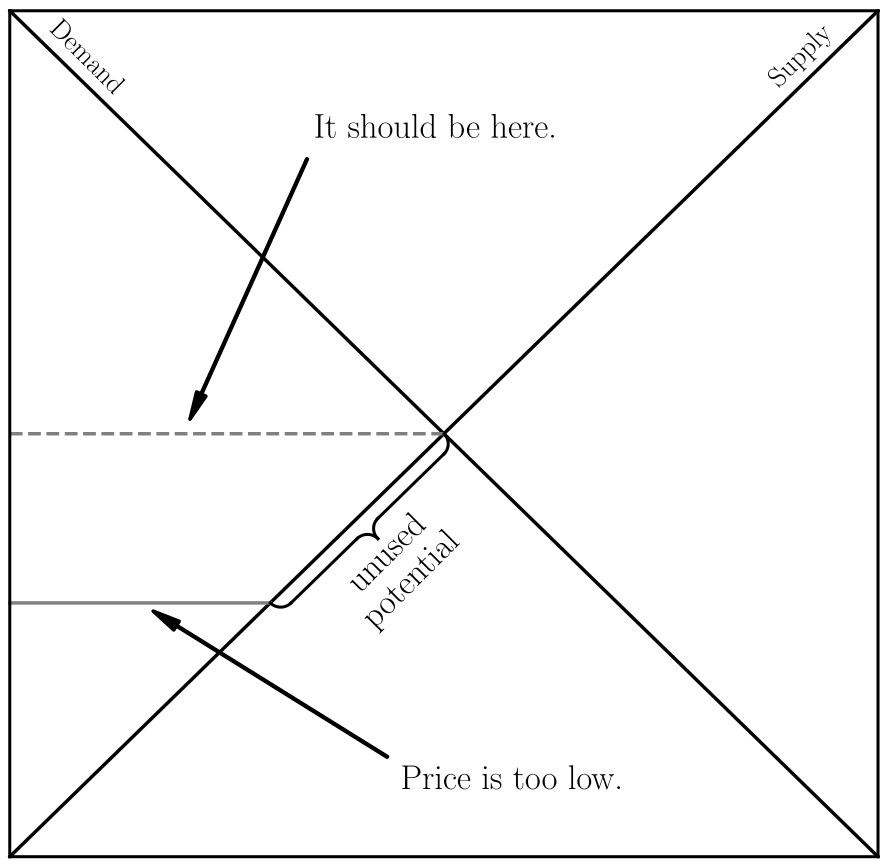

Figure 1

If demand exceeds supply at the current price, they reason, then the proper thing to do is to raise price and bring demand and supply back into agreement. $^{60}$ Only then will every unit of output for which value to consumers (the demand price) exceeds the cost of production (the supply price) actually change hands, maximizing welfare. ${ }^{61}$

The trouble with this tale is that the economic problem created by a demand surge is not that the surge artificially pushes the market price below the level that would equilibrate supply and demand, such that inventory that could be sold is left to rot, as would be the case for a market

\footnotetext{
${ }^{60}$ See Murphy, supra note 2. Figure 1 depicts a downward-sloping demand curve, so the firm would not actually wish to choose the price that equilibrates supply and demand in Figure 1; instead, the firm would choose a higher price to maximize profits. Technically, only a firm facing a flat demand line - meaning a demand line determined by a competitive market - would choose the price that equilibrates supply and demand. But it is hard to imagine competition making demand lines flat during an unexpected surge in demand to which competitors presumably cannot instantaneously adjust output. But see infra note 62 . Practitioners' argument seems to be that raising prices at least could balance supply and demand, and so firms should be left alone to raise them.

${ }^{61}$ See id.
} 
described by Figure 1. The problem is that there is not enough actuallyexisting supply to satisfy demand at the price that would normally equilibrate supply and demand, because no one expected demand to be as high as it turned out to be (which is why demand is said to be "surging") and so no one bothered to produce the extra supply needed to satisfy the high demand. ${ }^{62}$ Genuinely unexpected surges in demand create, in other words, shortages, and the market therefore looks as it does in Figure 2.

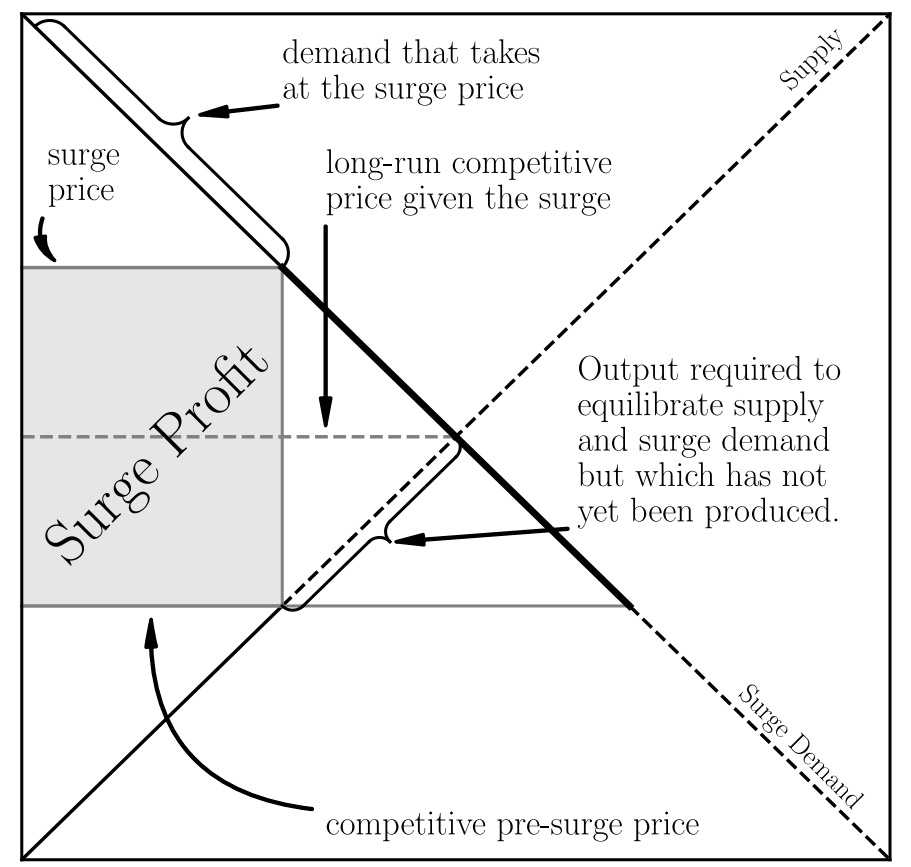

Figure 2

62 See Woodcock, The Economics of Shortages, supra note 33; Woodcock, The Hidden Shortages of the Market Economy, supra note 33. The output of some products can, of course, be increased instantaneously in response to an unexpected surge in demand. These are generally products that consist of information, and so exist in the same medium as price information, allowing them to be created in tandem with their prices. Thus the output of a music download can increase just as quickly as a download's prices. It follows that for this limited subset of products, an unexpected surge in demand creates no power to increase prices, for competitors can increase their output just as fast as prices increase, taking market share away from the firm and negating the profitability of the price increase. Firms will not, then engage in surge pricing with respect to this limited subset of products. Because there will be no surge pricing in this area to being with, it will not be necessary to exempt this area from the antitrust liability for surge pricing that will be discussed in Section II.C. 
Simply raising price to the equilibrating level will not actually equilibrate supply and demand because there is no supply to sell to those buyers who, at the current price, are unable to buy. ${ }^{63}$

The problem the firm confronts when demand surges is not the problem familiar to undergraduate economics students of finding the equilibrium price, but rather that of determining how to ration a temporarily limited supply of output when demand exceeds supply. ${ }^{64}$ The excess of demand in relation to supply is shown in Figure 2 by the excess length of the solid portion of the demand line in relation to the solid portion of the supply line (this excess length is shown in bold in the figure - the dashed portions of the demand and supply lines represent potential demand and supply, respectively, that does not actually exist). Every consumer occupying the solid portion of the demand line is willing to pay a price, labeled the "competitive pre-surge price" in the figure, that is high enough to cover the cost incurred by the firm in producing each unit of the output that the firm currently has available. But the output actually available, shown by the horizontal extent of the solid supply line, is clearly insufficient to satisfy demand, shown by the horizontal extent of the solid demand line, at this price.

Before the information age, firms generally had only one option available to deal with this problem: to continue to charge the price they would have charged absent the surge. ${ }^{65}$ The unusual case of ruinous competition aside, before the surge the firm would have chosen its price to, at the very least, cover the cost of producing its output, which means that the price would have equaled or exceeded the marginal cost of the most costly unit produced by the firm. ${ }^{66}$ A pre-information-age firm would

\footnotetext{
${ }^{6}$ See Woodcock, The Economics of Shortages, supra note 33; Woodcock, The Hidden Shortages of the Market Economy, supra note 33.

${ }^{64}$ See Stewart, supra note 53 ("[D]emand at what people would consider a reasonable price far exceeds supply. From an economics perspective, this is simply a rationing problem[.]").

65 See Alan S. Blinder Et Al., Asking About Prices: A New Approach to UNDERSTANDING PRICE STICKINESS 226-53 (1998).

${ }^{66}$ It is possible for the firm's price to have exceeded the cost of that marginal unit if the firm had market power and so faced a downward-sloping demand line. Indeed, such power is sometimes necessary to ensure that a firm can cover its fixed costs, which are in addition to the variable costs represented by a firm's supply line. (In Figure 2, the firm is assumed to have operated in a competitive market before the surge, and so the firm is shown to have charged a pre-surge price that intersects the supply line. If the firm had market power, that price line would hover above the supply line.) Either way, the important thing for purposes of this analysis is that the firm must have chosen the pre-surge price to equal or exceed the firm's costs of producing the amount of inventory that the firm intended to sell, otherwise
} 
continue to charge this cost-covering price during a demand surge, for lack of the technological ability to raise prices much more quickly than the firm would have been able to increase output in response to the surge in demand. ${ }^{67}$ Before the information age, prices were not only information, but also physical goods: bits of paper upon which numbers were written. To change a price meant distributing new physical bits of paper with new numbers written on them, just as meeting a surge in demand required ramping up production of physical goods. ${ }^{68}$ The speed with which prices could be changed was sometimes faster than the speed with which production could be increased - the process of printing and distributing a document is quicker than the process of building a new car, for examplebut the time required remained within the same order of magnitude as that of producing physical goods. ${ }^{69}$ That, in turn, meant that prices and output were both temporarily frozen during the surge in demand, at least for a time; neither could adjust immediately to take account of the shock.

Charging the pre-surge equilibrium price during a surge in demand causes the good to sell out. As Figure 3 shows, at that price all consumers on the solid part of the demand line are willing to buy, but supply, represented by the solid part of the supply line, covers only a fraction of the horizontal extent of that solid demand line, so the good must sell out.

the firm would not have chosen to remain in the market.

67 See Alan S. Blinder et Al., Asking About Prices: A New Approach to UNDERSTANDING PRICE STICKINESS 226-53 (1998).

${ }^{68}$ See id.

${ }^{69}$ See id. 


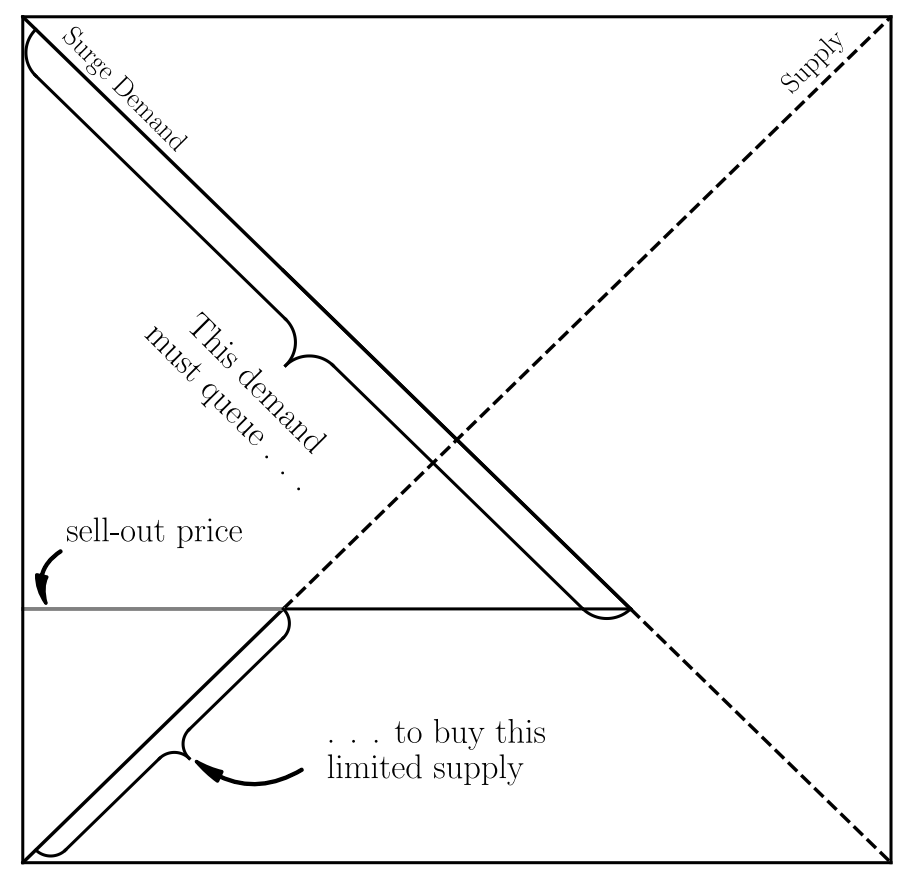

Figure 3

Which consumers in fact are able to buy the good depends on which manage to line up to purchase the good first; the allocative consequences of queuing will be discussed in detail in Section III.C. It is important for now to note that only consumers who can afford to pay the cost of production of any of the units of output will purchase them. Charging the pre-surge price rations based on antecedence - the principle of first-come-first-served - but it does not make a good free in the sense of available to first comers no matter what price they are willing to pay. Instead, it makes the good available only to those first comers who belong to the rarefied group of consumers who are willing to pay for even the highest-cost unit of production. For those at the head of the line must still pay the good's price. That is why, in Figure 3, the solid part of the demand line, which represents consumers who are willing to buy at the pre-surge price, extends no lower than the highest point on the solid part of the supply line, which represents the highest marginal cost of producing existing inventory. ${ }^{70}$

${ }^{70}$ For a graph that combines the lessons of Figure 2 and Figure 3, see Woodcock, The Economics of Shortages, supra note 33. If the pre-surge market is not competitive, and so the pre-surge price is above cost, then the solid part of the demand line would terminate at a level above that reached by the supply line, rather than, as pictured in Figure 3, 
Letting goods sell out at their pre-surge prices remains a common practice, as empty supermarket shelves during the pandemic attested. ${ }^{71}$ But the information-age ability to engage in surge pricing throws open a second option that, as we have seen, is increasingly popular, which is to ration access to goods using price. Using the Internet and algorithms instantaneously to adjust prices, a firm can choose a new price that only so many consumers as are willing to buy precisely the amount of the good on offer, and no more, are willing to pay. As Figure 2 shows, that price ensures that only the consumers with the highest willingness to pay, who fall along the highest part of the demand line, purchase the product. It also shows that surge pricing redistributes a sizable amount of wealth from consumers to the firm - an amount equal to the size of the shaded rectangle. This makes surge pricing a more profitable option than letting the good sell out at the pre-surge price (the case depicted in Figure 3). By rationing access based on willingness to pay, surge pricing not surprisingly extracts the maximum possible profit from consumers. ${ }^{72}$

A firm facing an unexpected increase in demand can ration with price because all firms, and not just the firm in question, will be unable to increase output instantaneously in response to the demand surge, at least so long as the firm is no worse at demand prediction than competitors. It follows that if the firm raises its prices, competitors will not be able to take market share from the firm by selling additional inventory at lower prices, and so the firm will have the power to raise its prices during the temporary period before output can increase. The downward slope of the demand line

terminating at the same level as the supply line.

${ }^{71}$ See Winnie Hu, Gone From Grocery Shelves, Now There's a Mad Dash to Find Them, N.Y. TIMES (May 11, 2020), https://www.nytimes.com/2020/05/11/nyregion/Coronavirussupermarkets-items-missing.html.

${ }^{72}$ It may be the case that raising price above that necessary to cause the amount demanded to equal pre-surge inventory - that is, raising price above the minimum necessary completely to ration existing inventory-would be profitable. This is a kind of surge pricing, and it would add to the natural scarcity associated with the unexpected surge in demand an artificial scarcity created by the firm, for then some units of pre-surge inventory would not sell. The analysis in this Article applies with equal force to this sort of surge pricing. But the discussion and figures explicitly treat only the case in which surge pricing precisely rations pre-surge inventory, creating no artificial scarcity. In other words, in this Article, the vertical line at the level of pre-surge output in Figure 2 will always define the surge price as the level at which the vertical line intersects with surge demand, as it does in that figure. But the arguments in this Article apply with equal force to the case in which it is profitable for the firm to raise its price above that level. The power created by the inability of output to adjust as quickly as price in response to surges in demand allows the firm to choose any price it wishes, including a price above that strictly necessary to ration access to pre-surge inventory, if such a price is more profitable. 
in Figure 2 (as well as Figure 1 and Figure 3) reflects this power, because the downward slope indicates that some consumers are willing to pay higher prices for the product. By contrast, if demand were flat, which occurs when the market is competitive, any price increase would cause demand to fall to zero.

The redistribution of wealth from consumers to the firm brought about by surge pricing makes surge pricing harmful to consumers, and indeed it harms consumers in the classic antitrust way of raising the prices that consumers pay for goods above the minimum prices needed to make the firm ready, willing, and able to remain in the market. ${ }^{73}$ That follows immediately from the assumption that the firm would have chosen its presurge prices to cover the cost of producing the output it believed would satisfy pre-surge demand. For if the firm chose its pre-surge prices to cover its costs, and the firm is unable to incur additional costs producing additional inventory in the short run, then the firm does not need to raise its prices in order to cover its costs, and so any increase in price during the period before the firm can ramp up production in response to the surge must be unnecessary to cover costs.

To be sure, were the firm able to increase output in response to the surge in demand, then an increase in price might be necessary to cover the cost of bringing more expensive units of output to market. But because the firm cannot adjust output instantaneously in response to the surge in demand, and, thanks to surge pricing, the firm now has the power to increase price instantaneously in response to the surge in demand, the firm now can always raise prices before higher prices are needed to pay for increased output. ${ }^{74}$ During that period when output remains fixed, any increase in price by the firm is an instance of surge pricing and necessarily harms consumers. ${ }^{75}$ The contrast between surge pricing and selling out is summarized in Figure 4.

\footnotetext{
${ }^{73}$ For liability to exist, antitrust requires either proof of harm to consumers or, in the case of per se rules, actions from which harm to consumers may almost always be inferred. See Steven C. Salop, Question: What Is the Real and Proper Antitrust Welfare Standard? Answer: The True Consumer Welfare Standard, 22 LOY. CONSUMER L. REV. 336, 336-47 (2010); Broadcast Music, Inc. v. Columbia Broadcasting System, Inc., 441 U.S. 1, 723-24 (1979). Consumers can be harmed only by the charging of prices in excess of costs, and costs, in the economic sense, are minimum payments necessary to make a firm ready, willing, and able to produce. See William J BAUMOL, ECONOMIC THEORY AND OPERATIONS ANALYSIS 593 (4th ed. 1977).

${ }^{74}$ See Ramsi A. Woodcock, Toward a Per Se Rule against Price Gouging, CPI ANTITRUST Chron. (Sep. 2020), at 51-52.

${ }^{75}$ See id. at 51.
} 


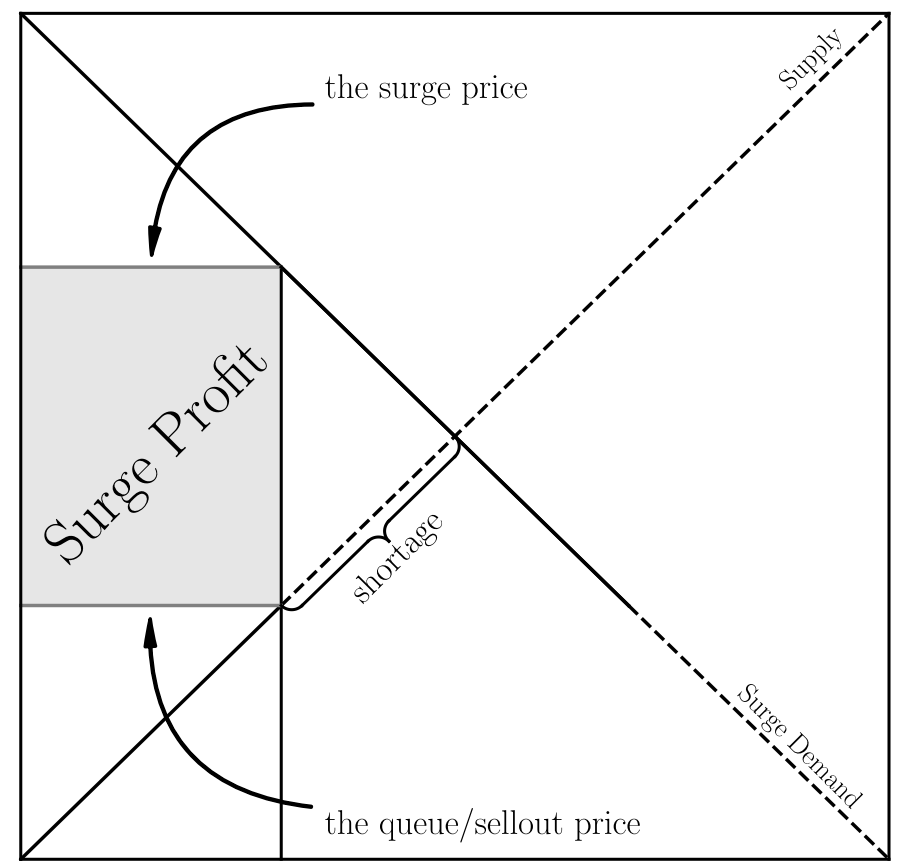

Figure 4

\section{Antitrust Liability}

\section{The Existence of Anticompetitive Conduct and Monopoly Power}

Legislatures could respond to this problem by banning the practice of surge pricing, which would be easy to do because surge pricing requires unique software and systems that enforcers can easily identify and shut down. ${ }^{76}$ But surge pricing also has an anticompetitive characteristic that makes it a good candidate for condemnation under existing antitrust laws. ${ }^{77}$ Surge pricing's anticompetitive characteristic is that it makes competition weaker. Regardless of the structure of the market before the surge in demand, whether the market had one firm charging a monopoly price, or

${ }^{76}$ Cf. William J. Niejadlik, A Spotlight on Total Offer Optimization, AMADEUs THOUGHT LEADERSHIP PAPER (2017), at 3, https://amadeus.com/documents/en/airlines/researchreport/a-spotlight-on-total-offer-optimization-web.pdf (marketing "revenue management" systems to airlines).

77 See generally 15 U.S.C. $\S \S 1,2$ (2018). 
many firms competing prices down to costs, the pre-surge market price always reflects competitive pressure of some kind. A firm may be a monopolist in a particular market and still charge a price that reflects competitive pressures because all products compete with other products to some extent, even a monopolist's. ${ }^{78}$ The firm that monopolizes all the aluminum in the country cannot charge too high a price, for example, because buyers must have some cash left over to buy food. It follows that aluminum competes with food: not hard enough to prevent an aluminum monopolist from charging a price in excess of cost, but hard enough to force the aluminum company to choose a price low enough to allow customers some room in their budgets for food. Firms in more competitive markets naturally face even more competitive pressure on price.

Without surge pricing, the effects of this competitive pressure extend into the surge period, because, as already observed, firms cannot raise their prices instantaneously in response. ${ }^{79}$ A firm that cannot raise prices before the surge because competitors wait in the wings, for example, is forced to continue charging the same price, even though the unexpected increase in demand renders those competitors unable to increase their prices in response to any price increase by the firm, allowing the firm, as we have seen, to raise prices should the firm have the technical capacity to do so.

This is true even for the monopolist who has no direct competitors waiting in the wings. The very fact that demand is surging for the monopolist's product implies that buyers of other products are now willing to devote more of their income to the monopolist's product, and so firms in other industries wishing to compete for those dollars may now wish to produce the monopolist's product. ${ }^{80}$ But of course they cannot ramp up production of the monopolist's product instantaneously, and so the monopolist is free to raise prices during the surge without fear of competition, something the monopolist could not do before the surge, when consumers were unwilling to divert more of their cash from other industries. Before the advent of surge pricing, the monopolist would have continued to charge the pre-surge price anyway, because the monopolist

\footnotetext{
78 See Edward Hastings Chamberlin, The TheOry OF MONOPOlistic COMPetition: A RE-ORIENTATION OF THE THEORY OF VALue 65 (7th ed. 1956) ("But if, in order to possess a perfect monopoly, control must extend to substitutes, the only perfect monopoly conceivable would be one embracing the supply of everything, since all things are more or less imperfect substitutes for each other.’).

79 See Alan S. Blinder et Al., Asking About Prices: A New Approach to UNDERSTANDING PRICE STICKINESS 226-53 (1998).

80 See HovenKAMP, supra note 14, at 356 (observing that "high profits will attract other producers into the market").
} 
would have lacked the technical ability to raise prices, despite the demise of the competitive pressures that once constrained the monopolist's pricing.

It follows that technological limitations on a firm's ability to raise prices prolong the effects of competition in the pre-surge period into the surge period, and that surge pricing, in eliminating those technological limitations and enabling instantaneous price adjustment, destroys those effects of competition. ${ }^{81}$ For this reason, surge pricing should count as anticompetitive conduct under the antitrust laws.

Most conduct that the courts classify as anticompetitive under the antitrust laws is directly anticompetitive in the sense that it hobbles competitors, preventing them from continuing to exert downward pressure on prices. ${ }^{82}$ Surge pricing does not drive competitors from markets and so is not anticompetitive in this way. But some conduct that the courts classify as anticompetitive is, like surge pricing, only indirectly anticompetitive in the sense that it blunts the effects of competition, rather than competition itself. The antitrust laws treat price-fixing as anticompetitive conduct even when the price fixing amounts to no more than formalization of the tacit terms of pre-existing, consciously-parallel conduct. ${ }^{83}$ The agreement does not, in this case, directly harm competition - the cartel members did that when they first started tacitly colluding-but the agreement does allow the cartel members more fully to exploit their power. ${ }^{84}$ Firms colluding tacitly can nudge each other in the direction of charging higher prices, by suggesting a game of follow the leader, but they cannot pick a price target for the group and ensure that each member hits it; communication is required for that. ${ }^{85}$

\footnotetext{
${ }^{81}$ See Woodcock, supra note 74, at 53-54.

${ }^{82}$ For example, when antitrust treats a refusal to deal with a competitor as anticompetitive it does so because the refusal harms the competitor by denying it an essential input. See HOVENKAMP, supra note 14, at 383 (noting that liability for a refusal to deal exists under the antitrust laws only if harm to "at least one rival" can be shown); Aspen Skiing Co. v. Aspen Highlands Skiing Corp., 472 U.S. 585, 610 (1985) (condemning a firm that made "a deliberate effort to discourage its customers from doing business with its smaller rival").

83 See HovenKamp, supra note 14, at 327-35 (discussing the illegality of naked price fixing under any circumstance).

84 See Miguel A. Fonseca \& Hans-Theo Normann, Explicit vs. Tacit Collusion-The Impact of Communication in Oligopoly Experiments, 56 EUR. ECON. REV. 1759, 1754 (2012) (finding experimental evidence that tacit collusion raises prices and explicit collusion raises them even more); cf. Phillip Areeda, Market Definition and Horizontal Restraints The Economics of Horizontal Restraints, 52 ANTITRUST L.J. 553, 564 (1983) (arguing that "a merger which reinforces pre-existing . . . oligopoly pricing" violates the antitrust laws).

${ }^{85}$ See Fonseca \& Normann, supra note 84, at 1770 (observing that "[c]ommunication helps firms coordinating on a price or more sophisticated pricing patterns" and that communication is used in "conflict mediation to avoid the decline of prices").
} 
Thus price fixing in this case solves a technical problem regarding the picking of prices that magnifies the effects of a pre-existing decline in competition. Surge pricing does the same and so should, similarly, be treated as anticompetitive. ${ }^{86}$

Liability under the antitrust laws usually requires, in addition to proof of anticompetitive conduct, proof that the defendant has monopoly power, defined as the power profitably to raise prices. ${ }^{87}$ That requirement is necessarily met for any firm engaged in surge pricing, because surge pricing is the act of raising prices above pre-surge prices that cover costs. There should be no need for plaintiffs to prove monopoly power in an action alleging surge pricing, because the courts do not require proof of power where the challenged action is certain or almost certain to harm consumers. In this case, liability is said to be "per se"; surge pricing should be per se illegal. ${ }^{88}$

\section{A Proposed Test}

A per se rule against surge pricing should have the following elements. A firm that (1) uses algorithms to set prices, (2) experiences a surge in demand, and (3) increases its prices in response to that surge (4) faster than the firm increases its supply violates the antitrust laws-in particular, Section 2 of the Sherman Act, which prohibits anticompetitive conduct by single firms. ${ }^{89}$

The first element - the use of algorithms - ensures that the firm has taken an affirmative step to cause the speed with which the firm can change prices to outstrip the speed with which the firm can adjust output. Firms have probably always had some power to identify demand surges and react to them faster than they can increase output. As noted above, price stickers can be changed on cars quicker than cars can be produced. It would not be anticompetitive for firms to exercise this power any more than it would be anticompetitive for a firm that obtains a monopoly position by accident to charge a monopoly price. ${ }^{90}$ What makes surge pricing anticompetitive is that the practitioner uses algorithms to augment whatever pre-information-

\footnotetext{
${ }^{86}$ See Woodcock, supra note 74, at 54.

${ }^{87}$ See Kirkwood, supra note 27, at 1173-74.

${ }^{88}$ See Broadcast Music, Inc. v. Columbia Broadcasting System, Inc., 441 U.S. 1, 19-20 (1979) (stating that a rule of per se illegality applies only to a practice that "facially appears to be one that would always or almost always tend to restrict competition").

${ }^{89}$ See 15 U.S.C. § 2 (2018); HovENKAMP, supra note 14, at 349.

${ }^{90}$ See Oliver E. Williamson, Dominant Firms and the Monopoly Problem: Market Failure Considerations, 85 HARV. L. REV. 1512, 1513 (1972).
} 
age powers the firm may have had to increase prices faster than output. The first element captures this important distinction.

The final three elements establish the existence of consumer harm. The second element - that demand surge - ensures that any price increase is not necessary to cover the costs, inclusive of fixed costs, of producing current inventory. That will always be the case if demand surges, because firms would have chosen their pre-surge prices to cover their costs, and an increase in demand guarantees that they will be able both to charge at least that pre-surge price and to sell out of their inventory at that price. If, by contrast, demand were to fall unexpectedly, then a price increase might be necessary to cover costs, inclusive of fixed costs, on a smaller-thanexpected volume of sales. ${ }^{91}$ The second element rules out this justification for a price increase. The third element establishes that a price increase has in fact occurred. And the fourth element establishes that the price increase could not have been necessary to pay for the production of additional, postsurge inventory because the price increase happened before output could be increased. If each of these three elements is met, it follows that tyhere was a price increase that was not necessary to cover the cost, inclusive of fixed costs, of either pre- or post-surge inventory and was therefore harmful to consumers.

\section{Objections Based on Innovation and Risk}

One common objection to claims in antitrust that a particular practice always harms consumers and so should be proscribed is that higher prices are needed to pay for costs of innovation that ultimately make consumers better off, even after taking the higher prices into account. ${ }^{92}$ Such arguments do not apply here because the increase in demand is not expected, and the firm therefore could not have taken the increase into account in planning its research and development expenditures. Surge pricing allows firms to extract profits from chance, making them pure profits.

Another common objection is that what looks like profit-taking by firms is really compensation for risk. ${ }^{93}$ In the context of surge pricing, the

\footnotetext{
${ }^{91}$ See infra Figure 9.

92 See Verizon Commc'ns Inc. v. Law Offices of Curtis V. Trinko, 540 U.S. 398, 407 (2004); Richard M. Brunell, Appropriability in Antitrust: How Much Is Enough?, 69 AnTitRust L.J. 1, 1-2 (2001); Ramsi A. Woodcock, Inconsistency in Antitrust, 68 U. MIAMI L. REV. 105, 126-36 (2013) (critiquing this argument from a different perspective).

${ }^{93}$ See Trinko, 540 U.S. at 407 ("The opportunity to charge monopoly prices - at least for a short period-is what attracts 'business acumen' in the first place; it induces risk
} 
argument would be that firms take the possibility that demand will be more or less than expected into account in choosing how much to produce and indeed in choosing what costs to incur in production. If, in the event, demand turns out to be just sufficient to cover the costs of production, the argument goes, then so much the better. But, the argument continues, if demand turns out to be greater than expected, and the firm uses surge pricing to earn a profit as a result, that is simply compensation for the risk, borne by the firm, that demand could have turned out to be less than expected and that the firm might have suffered a loss as a result. The firm would not have been willing to bear the downside risk if there had been no possibility of an upside. It follows that we cannot assume that the pre-surge price that the firm actually chooses will be sufficient to cover the firm's costs of production, and so we cannot assume that any price increase associated with a demand surge represents above-cost pricing. Instead, because the firm uses the possibility of profits from surge pricing to offset the possibility of losses from a shortfall in demand, it is always possible that surge pricing is necessary to cover the costs associated with bearing risk and the profits that surge pricing generates are not therefore true profits in the economic sense of revenues not needed to cover costs.

The trouble with this argument is that it cannot be the case that all of the additional revenues afforded to firms by surge pricing are always necessary to accommodate risk. ${ }^{94}$ If that were true then there could be no such thing as economic profit, understood as revenues in excess of costs. Whatever revenues a firm were to earn, no matter how large, would simply be cost, and consumers would not, as an economic matter, be entitled to any share of the gains from trade; indeed, there would be no gains from trade because any gains would be understood to be necessary to accommodate risk and so would not count as true gains at all. ${ }^{95}$ If we tend to assume that this is not the case about other kinds of costs - we draw demand curves to start out substantially above supply curves in conventional economic modeling, implying that there are gains from trade - then it would be strange to relax

taking[.]"); Henry G. Grabowski \& Joseph A. DiMasi, $R \& D$ Costs and Returns to New Drug Development: A Review of the Evidence, in THE OXFORD HANDBOOK OF THE ECONOMICS OF THE BIOPHARMACEUTICAL INDUSTRY 21, 38-40 (Patricia M. Danzon \& Sean Nicholson eds., 2012) (arguing that large accounting profits on blockbuster drugs are not necessarily indicative of economic profits because most drugs fail and the profits on the blockbusters may be needed to pay the costs of the failures).

${ }^{94}$ Cf. Ramsi A. Woodcock, The Antitrust Case for Consumer Primacy in Corporate Governance, 10 UC IRVINE L. REV. 1395, 1415-18 (2020) (rejecting this argument outside of the risk context).

${ }^{95}$ See id. 
the assumption in the case of the cost of accommodating risk. ${ }^{96}$

If in fact not all of the profits generated by surge pricing are necessary to offset the risk of losses, one may ask whether any of the profits generated by surge pricing might be necessary to offset the risk of losses. For even without surge pricing, there are profits available to the firm that might offset the possibility of losses. The firm can, for example, build a profit cushion into the pre-surge price that the firm chooses. That is, the firm can choose a pre-surge quantity and price that, if the expected amount of demand materializes, will generate a profit, regardless whether a surge occurs, and that profit would serve to offset the risk that demand will fall short. If all firms in the market are prevented from engaging in surge pricing, then they may all choose to add such a cushion, and so this abovecost price will not be competed away. Even if all firms in the market do not build in such a cushion, the firm may be able to avoid having its own cushion competed away by creating innovative products that competitors are unable to replicate. The firm can also use pre-information-age toolssuch as back-of-envelope guessing at the extent to which demand has surged, rather than using algorithms to model it - to increase prices in the event of a surge, allowing for a modest surge-based profit to offset the risk of losses.

But although it is possible that no profits are necessary to offset the risk of losses, it is not certain that this is true in every case. The possibility that surge pricing, or some fraction of the profits generated by surge pricing, might actually be necessary to offset the risk of losses seems to force antitrust liability to turn on the facts of individual cases - the magnitude of the surge prices chosen by firms, the magnitude of possible losses, and the probabilities associated with success and failure. ${ }^{97}$ This would seem to preclude a per se rule against surge pricing, which can be imposed only if surge pricing can be shown almost always to harm consumers, in every case.

The entire problem of compensation for risk can, however, be avoided by appeal to recent history. ${ }^{98}$ For until about a decade ago, no firm engaged

\footnotetext{
96 See VARIAN, supra note 34, at 261 (providing a good example of how demand and supply are usually drawn).

${ }^{97}$ Deciding how much compensation really is necessary to offset any cost, not just the cost of risk, is a notoriously difficult problem in economics, so this case-by-case analysis would be especially costly and uncertain of execution. See W. KIP VISCUSI ET AL., ECONOMICS OF REGULATION AND ANTITRUST 539-57 (5th ed. 2018).

98 See Ramsi A. Woodcock, Big Data, Price Discrimination, and Antitrust, 68 HASTINGS L.J. 1371, 1402-3 (2017) (making the similar argument that personalized pricing will not be needed to reward innovation if the economy is innovative enough today).
} 
in surge pricing. ${ }^{99}$ If it were true that firms need surge pricing to offset the risk of a shortfall in demand, then one would expect that, up until ten years ago, there would have been many markets in which firms could not charge prices sufficiently large to cover the costs associated with the risk of a shortfall in demand, and so, in these markets, firms produced less than they optimally should have produced, or fielded products that were of lower quality than they optimally should have been, or failed to enter the market at all when entering the market would have been good for the economy. ${ }^{100}$ But do we really believe this to be true? Did the economy of ten years ago grow at a slower rate than does the economy of today? ${ }^{101}$ Did the public experience the economy of ten years ago as too small, insufficiently innovative, or lacking in important markets? ${ }^{102}$ Conversely, can we attribute any meaningful part of the economic growth of the past ten years to the introduction of surge pricing? ${ }^{103}$ The answers all appear to be no. If the economy was doing just fine without surge pricing, then we can infer that surge pricing is not, as a general, economy-wide matter, necessary to offset the risk of losses and so can safely be prohibited. ${ }^{104}$

\section{E. More on How Demand Surges}

So much for the antitrust case against surge pricing. But what exactly is a surge in demand? There are in fact two kinds. The first, which is the focus throughout this Article, is the case in which demand increases at the margin, meaning that the amount of output demanded at the pre-surge price goes up: the marginal unit attracts additional demand, and the willingness of consumers to pay for that unit goes up, as shown in Figure 5 for the case of an initially competitive market (which is the case also depicted in Figure 1, Figure 2, and Figure 3) and in Figure 6 for the case of an initial market in which the firm has some power over price. In Figure 5, the marginal unit is defined by the point at which pre-surge demand equals supply; surge

\footnotetext{
${ }^{99}$ See id.

100 See id.

${ }^{101}$ No. If anything, growth rates have been falling. See U.S. GDP Growth Rate 1961-2021, https://www.macrotrends.net/countries/USA/united-states/gdp-growth-rate (last visited Jul. 30, 2021).

102 Probably not. See How America Risks Losing Its Innovation Edge, TIME, https://time.com/longform/america-innovation/ (last visited Jul. 30, 2021).

103 There appear to be no studies of same, but that in itself suggests that economists do not see an important macroeconomic role for surge pricing.

${ }^{104}$ See Woodcock, Big Data, Price Discrimination, and Antitrust, supra note 98, at 14023.
} 
demand is higher at this point. In Figure 6, the marginal unit is defined by the point at which the monopoly price intersects pre-surge demand. Surge demand is again higher at this point.

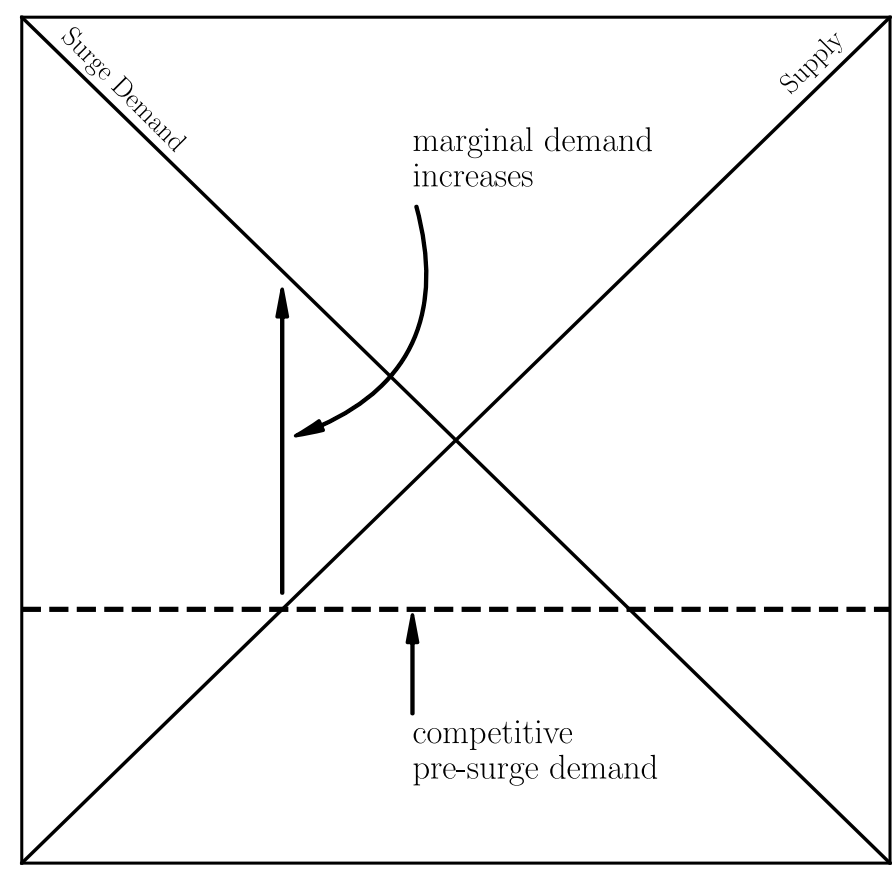

Figure 5 


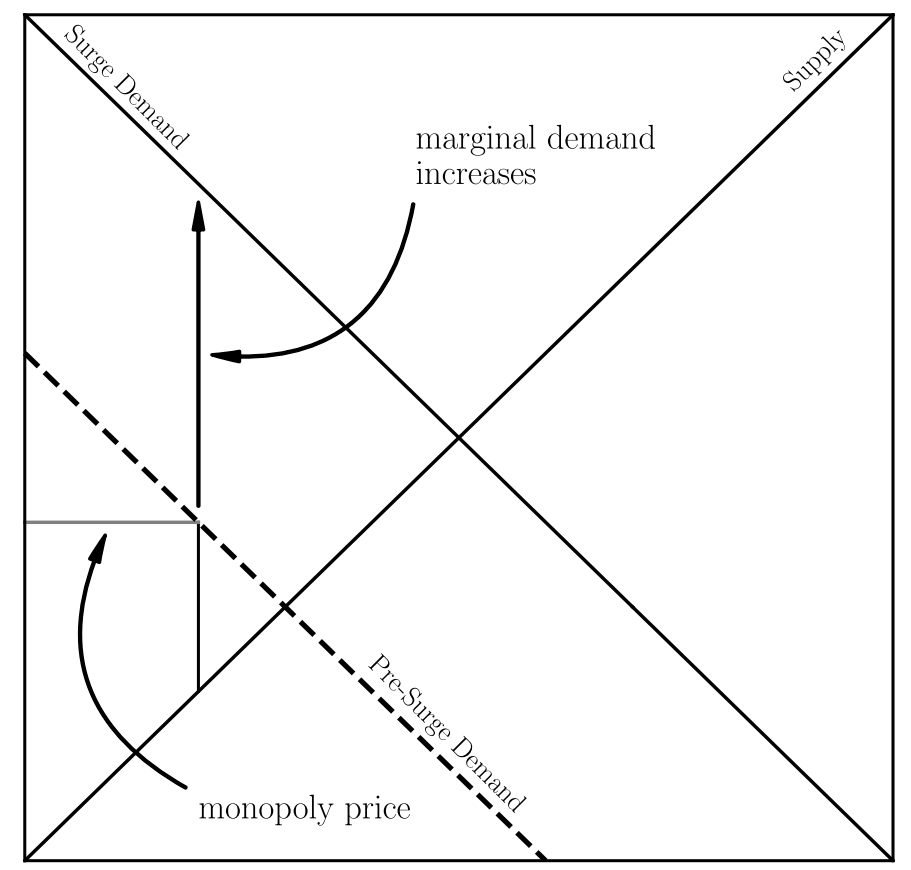

Figure 6

The second kind of demand surge is that in which only demand for inframarginal units of production goes up, as shown in Figure 7 for the case of an initially competitive market and in Figure 8 for the case of an initial market in which the firm has some power over price. In Figure 7, there is no increase in demand for the marginal unit, which is defined by the intersection of pre-surge demand and supply. Demand increases only for units to the left of that unit, which are the inframarginal units. In Figure 8, there is no increase in demand for the marginal unit, which is defined by the intersection of the monopoly price and pre-surge demand. Demand increases only for units to the left of that unit, which are, again, the inframarginal units. 


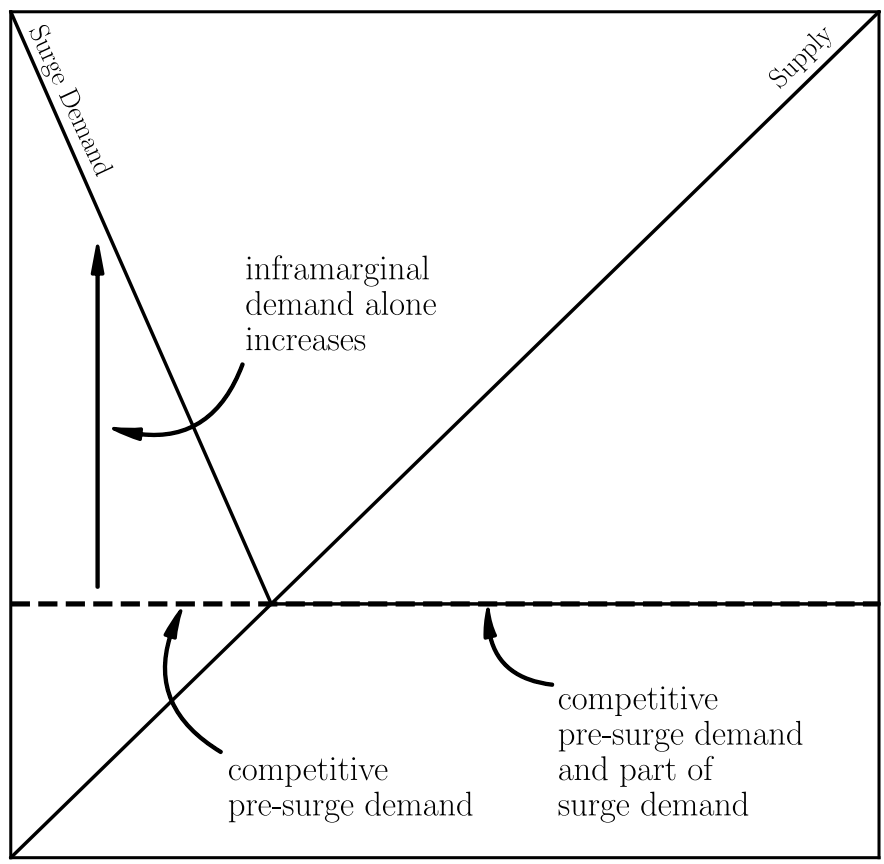

Figure 7

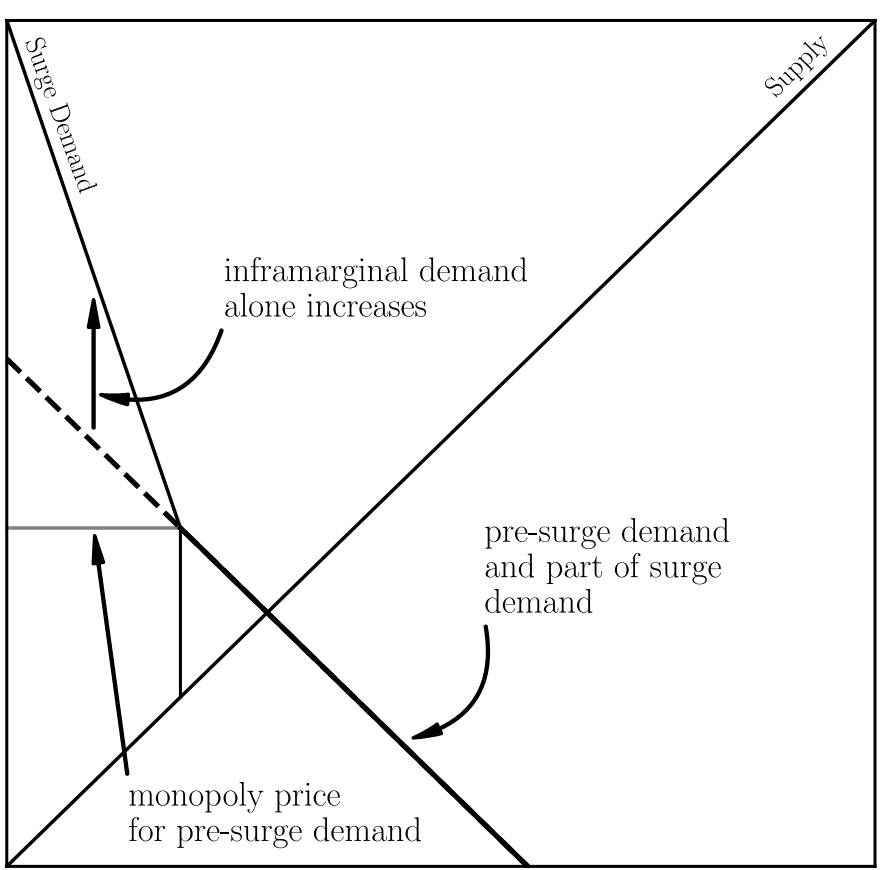

Figure 8 
In this case, there is no obvious surprise-induced shortage of the good created by the surge in demand, for the marginal consumer is still willing to pay no more than the pre-surge price and there is no additional demand for the marginal unit.

The same set of arguments regarding consumer harm, as well as the test for an antitrust violation described above, applies with equal force to surges in inframarginal demand as it does to surges in marginal demand, notwithstanding the apparent absence of a surprise-induced shortage in the case of a surge in inframarginal demand. The reason is that what is in short supply in the case of a surge in inframarginal demand are other differentiated products, rather than additional inventory of the same, undifferentiated product. ${ }^{105}$ Because firms cannot introduce new, differentiated products instantaneously in response to an unexpected surge in inframarginal demand, they can raise prices for existing, pre-surge products, and thereby harm consumers. ${ }^{106}$ But once enough time has elapsed for firms to introduce new differentiated products, the extra inframarginal demand for their pre-surge products will melt away as consumers purchase the newly-introduced differentiated products instead. ${ }^{107}$ Similarly, in the case of a surge in marginal demand, firms with time bring additional units of the product to market, satisfying the excess demand and eliminating the power over price initially enjoyed by firms during the surge period. ${ }^{108}$

In the antitrust literature, surges in inframarginal demand are often associated with innovation and product improvement: the firm improves its product, causing consumers to prefer the product over substitutes, increasing consumers' willingness to pay for the product. ${ }^{109}$ As mentioned above, some scholars go on to argue that the higher profits made possible by the increase in demand may be necessary to cover the research and development costs associated with improving the product. $^{110}$ An

\footnotetext{
105 See CHAMBERLIN, supra note 78, at 115.

${ }^{106}$ See id.

107 See id.

108 One difference between the way the story plays out for surges in inframarginal demand relative to surges in marginal demand is that in the case of inframarginal demand, surge pricing always causes some artificial scarcity - for price increases when marginal demand has not shifted always require a firm to leave some existing inventory unsold-whereas in the case of marginal demand, surge pricing only sometimes leads to artificial scarcity. See supra note 72.

109 See SCHERER \& Ross, supra note 39, at 623; Frederic M. Scherer, First Mover Advantages and Optimal Patent Protection, 40 J. TECH. TRANSFER 559, 563-64 (2015); Woodcock, supra note 92, at 126-36.

110 See Brunell, supra note 92, at 1-2.
} 
unexpected surge in demand certainly may result from a product improvement that has an unexpectedly positive effect on demand. But if the surge in demand really is unexpected, then, as in the case of a surge in marginal demand, there can be no need for prices to increase in order to cover research and development costs, because the firm would have set prices to cover costs assuming the expected level of demand. It follows that proscribing surge pricing should have no effect on the innovativeness of firms. ${ }^{111}$

\section{F. Distinguishing Surge Pricing from Dynamic Pricing}

The same pricing technology that has enabled surge pricing has also enabled firms to adjust their prices quickly in response to unexpected shortfalls in demand. ${ }^{112}$ Antitrust cannot, however, prohibit such shortfall pricing, at least on a per se basis, because shortfall pricing does not always harm consumers; indeed, it often serves only to help firms cut their losses, not to charge above-cost prices and redistribute wealth from consumers. ${ }^{113}$ The reason is that a demand shortfall may eliminate demand for the marginal unit of production, which means that the firm may no longer be able to sell all of its inventory at the pre-surge price that the firm chose to cover its costs. Depending on how demand declines, the firm will be able to maximize the income, net of variable costs, that it can use to cover its fixed costs (this net income being called "quasi-profits") either by raising its prices or lowering them, as shown in Figure 9 and Figure 10.

\footnotetext{
${ }^{111}$ Cf. Woodcock, Big Data, Price Discrimination, and Antitrust, supra note 98, at 1402-3 (arguing that, outside of the surge pricing context, aggressive antitrust enforcement in response to the rise of personalized and other data-driven forms of pricing should have no effect on innovativeness either, but for different reasons).

112 See Cross et al., supra note 47, at 10 (relating that the initial impetus behind American Airlines' pioneering of "yield management" algorithms was to find a way to lower price selectively in response to shortfalls in demand).

${ }^{113}$ Cf. id.
} 


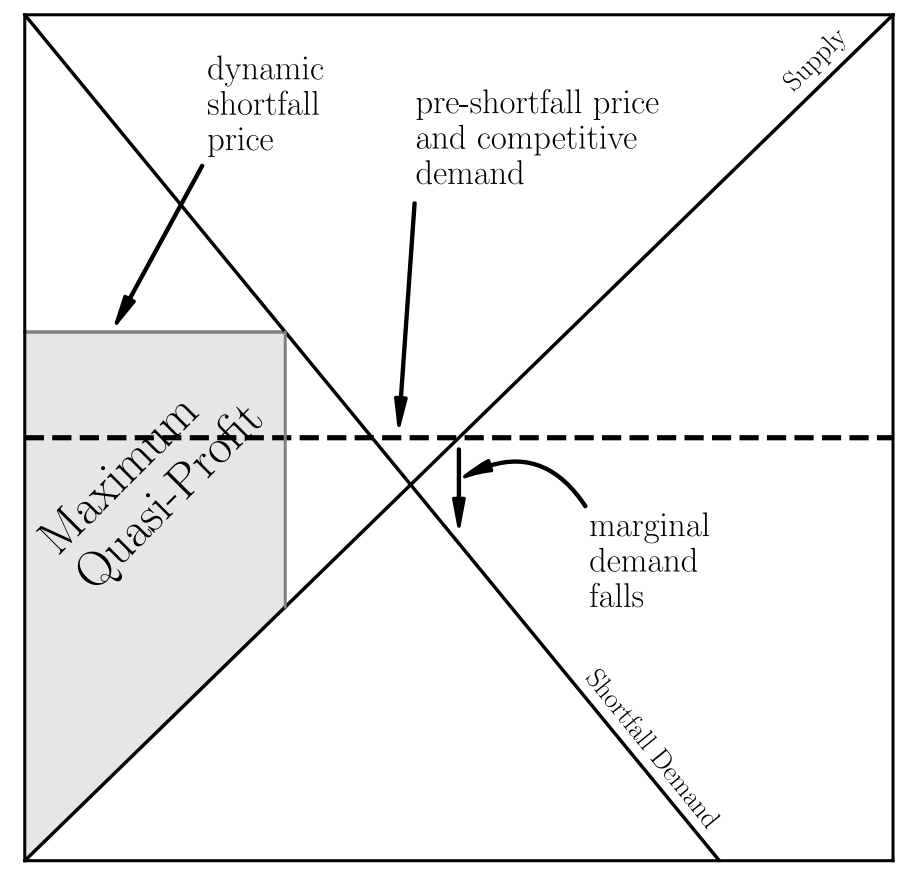

Figure 9

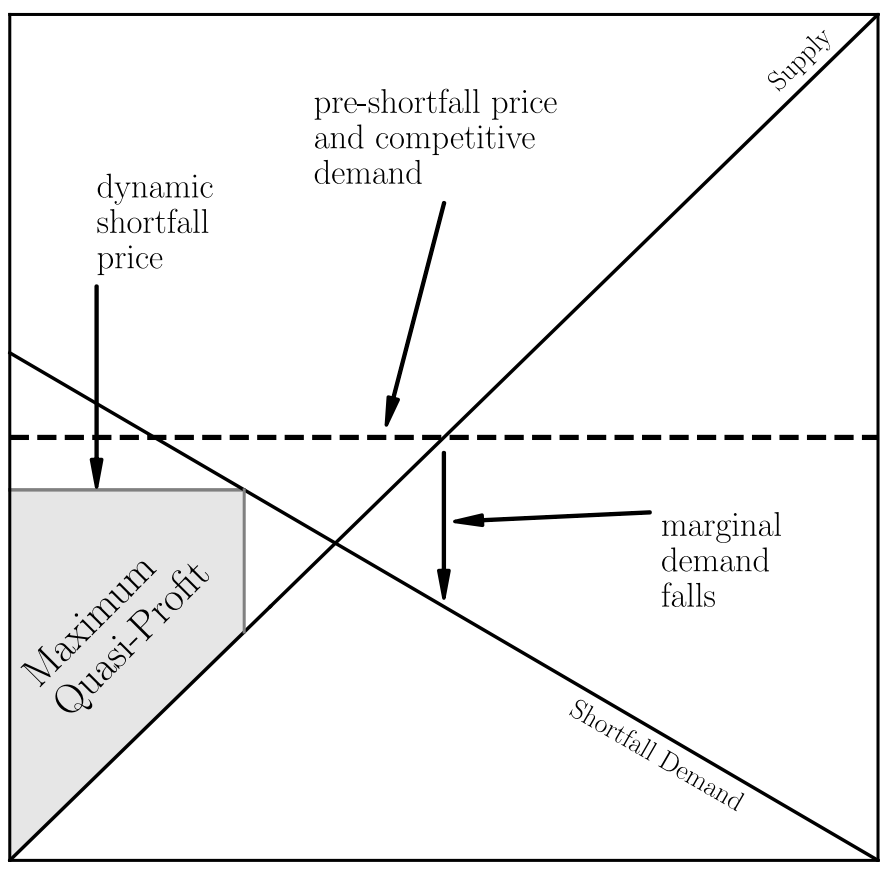

Figure 10 
But whether quasi-profits so maximized will cover the firm's fixed costs will depend on the size of those costs and the magnitude of the demand reduction. If quasi-profits so maximized do not cover the firm's fixed costs, or only just barely cover them, then there will be no harm to consumers. By contrast, we have seen that in the case of a surge in demand, it is possible to conclude that the firm will always choose to increase prices, and that any such price increase will raise quasi-profits above fixed costs, harming consumers. Consumers will be harmed because, as we have also seen, a surge in demand does not prevent the firm from continuing to sell its entire inventory at the pre-surge price that the firm chose to cover costs, including fixed costs, and so the only use the firm will have for a change in prices will be to charge above-cost prices and thereby to earn a profit.

In other words, in the case of a demand shortfall, the consequent reduction in sales at the pre-surge price potentially puts the firm in a lossmaking position if the firm continues to charge the pre-surge price, and so it does not follow that any price change made by the firm in response must necessarily generate revenues in excess of costs in order for the firm to be willing to undertake it. As a result, the consumer harm that is the flipside of profit taking cannot necessarily be inferred from a demand shortfall. The general practice of dynamic pricing, which includes algorithmic pricing in response both to unexpected surges in demand and in response to unexpected shortfalls in demand, therefore cannot be condemned per se, unlike the subset of dynamic pricing that is surge pricing, which can be condemned in toto.

\section{ADDRESSING COUNTER-ARGUMENTS}

Three objections to prohibiting surge pricing have so far been considered here. One was the classic Chicago School admonishment that what looks like profit-taking may well be necessary to cover the costs of innovation. ${ }^{114}$ We rejected this objection because firms choose their presurge prices to cover their costs, including research and development costs, so prohibiting surge pricing is no threat to innovation. Another objection was that what looks like profit-taking may well be necessary to provide compensation for risk. We rejected this objection because the vibrancy of the economy before the advent of surge pricing suggests that firms do not need surge pricing to give them an incentive to take risks. The final objection that we considered was that surge pricing covers the cost of

\footnotetext{
${ }^{114}$ See supra Section II.C.2.
} 
ramping up output to meet a surge in demand. ${ }^{115} \mathrm{We}$ saw that there are no increased output costs for surge pricing to cover, however, because surge pricing raises prices faster than output can adjust, so firms charge surge prices on existing inventory, not on new inventory produced in response to the surge.

There are three other, more interesting objections, which will be the subject of this Part. One is that surge pricing is a signal to prospective entrants into the market that there is money to be made in satisfying the surge in demand. ${ }^{116}$ According to this objection, surge pricing serves to hasten an increase in industry supply to meet the surge in demand, even if surge pricing itself is not required to pay for such an increase. Another objection is that surge pricing avoids the dislocations associated with the alternative of selling out, because surge pricing does not force buyers to wait in lines to acquire scarce inventory. ${ }^{117}$ The final objection is that surge pricing rations access to the limited inventory available during a demand surge in favor of those who place the highest value on the inventory whereas the alternatives of letting the good sell out does not. ${ }^{118}$

\section{A. Surge Pricing Signals}

The core of the signaling argument is that the high prices set by surge pricing tell other firms that they might be able to charge similarly high prices if they ramp up production to satisfy the excess demand associated with the surge. ${ }^{119}$ The idea is that there may be other firms that can bring more of the product, or a close substitute, to market more quickly than the firm can ramp up its own output in response to a surge in demand. ${ }^{120}$ Before the surge, these firms might have chosen not to enter the market because their production costs exceeded those of the firm and so they would not

\footnotetext{
115 See supra Section II.B.

116 See infra Section III.A.

${ }^{117}$ See infra Section III.B.

118 See infra Section III.C.

119 See J.D. Tuccille, Price-Gouging Laws Will Do More Harm Than Good During the Coronavirus Pandemic, REASON (Mar. 16, 2020), https://reason.com/2020/03/16/pricegouging-laws-will-do-more-harm-than-good-during-the-coronavirus-pandemic/ ("[R]ising prices tell . . . manufacturers and distributors that they should increase production[.]"); Antony Davies \& James Harrigan, 'Price Gouging' During Crisis a Good Thing, TRIBLIVE, $\quad$ https://triblive.com/opinion/antony-davies-james-harrigan-price-gougingduring-crisis-a-good-thing/ ("The higher the price of surgical masks, the more incentive manufacturers have to work around the clock to make more, and to feed them into the supply lines.").

${ }^{120}$ See Tuccille, supra note 119.
} 
have been able to match the pre-surge price charged by the firm. ${ }^{121}$ When the firm implements surge pricing in response to the surge in demand, however, the higher, surge prices tell these other firms that demand is likely now sufficiently large that they may be able to enter the market and charge the higher prices they need to charge in order to cover their higher costs. ${ }^{122}$ And so these firms will now enter the market and satisfy the excess demand. ${ }^{123}$ The surge pricing serves, in effect, as a way for the firm to call in the cavalry to increase industry-wide output. ${ }^{124}$

This argument acknowledges that surge pricing harms the firm's customers. Surge pricing is not needed to cover the firm's production costs because, as we have already seen, surge pricing raises prices faster than the firm can increase its output, and so the firm does not have any higher costs to cover at the time that the firm raises prices, making the price increases a pure wealth transfer from consumers to the firm. But, the argument goes, this harm is more than offset by the benefits consumers enjoy from more quickly obtaining access to additional output thanks to the response of competitors to the signal sent by the firm's surge prices.

If one actually attempts to add up the costs and benefits, the conclusion is not quite so clear. Depending on how demand surges - that is, depending on the shape of the demand curve during the surge - and depending on the prices charged by competitors that response to the price signal, consumers might actually be better off as a group without surge pricing, as shown in Figure 11.

\footnotetext{
${ }^{121}$ See id.

${ }^{122}$ See id.

${ }^{123}$ See id.

${ }^{124}$ See id.
} 


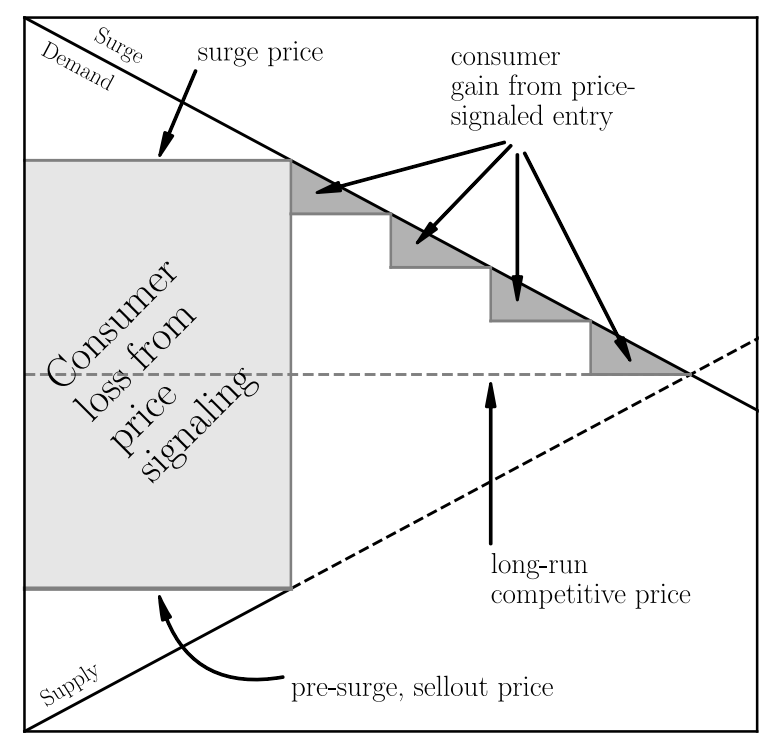

Figure 11

Competitors that take the surge price as a signal will tend to enter from the high end of consumer willingness to pay, and bid prices down, potentially creating the steps down in price shown in the figure. If the area above the steps is less than the area of the firm's profit rectangle, then consumers would be better off were price to stay at the pre-surge level and there to be no signaling or entry from competitors at all. This difficulty will not, however, be considered further. It will be assumed, for purposes of argument, that the harm of surge pricing is more than offset by the benefits of signaling-induced market entry.

The signaling argument will be challenged instead by the demonstration that the baseline world in which the firm continues to charge the pre-surge price and the good sells out, against which the costs and benefits depicted in Figure 11 are measured, fails to take into account the fact that selling out at the pre-surge price also sends a signal, one that might potentially create more benefits for consumers than the signal sent by surge pricing. ${ }^{125}$ The argument that surge pricing's signaling function makes consumers better off assumes that in the absence of surge pricing firms would sell out of their inventory at pre-surge prices and, unlike in the case of surge pricing, no signal would be issued that would beckon additional output into the market

125 See Woodcock, The Economics of Shortages, supra note 33; Woodcock, The Hidden Shortages of the Market Economy, supra note 33; Woodcock, supra note 74, at 55. 
from other firms. But there is no reason to suppose that a firm that foregoes surge pricing and sells out at the pre-surge price does not also send a signal to the market. ${ }^{126}$ To the contrary, the firm does in fact send a signal: the signal that the firm has sold out. ${ }^{127}$ It is just as easy for competitors to follow the firm's online product listing and learn that the product's price has surged as it is for competitors to follow the firm's online product listing and discover that the product has sold out at the pre-surge price. ${ }^{128}$ Moreover, the signal that a firm has sold out at the pre-surge price will induce competitors to enter the market and satisfy the excess demand. ${ }^{129} \mathrm{~A}$ competitor that observes that the firm has sold out without altering its prices can infer that there are likely some consumers in the market who are willing to pay at least a slightly higher price but who are unable to buy. ${ }^{130}$ So competitors that had been unwilling to enter the market because the competitor's costs were slightly higher than prevailing prices may now be willing to risk market entry at a slightly higher price. ${ }^{131}$

Because both signal, whether surge pricing is to be preferred over selling out depends on which signals in the way that most benefits consumers. Market entry in response to a sold out signal will differ from entry in response to a surge price signal, for initially only those firms that have production costs that are slightly higher than the pre-surge price will enter in response to a sold out signal. ${ }^{132}$ Higher-cost firms will hold back because the signal that a firm has sold out at the pre-surge price contains no information regarding how much more consumers are willing to pay to satisfy their excess demand only that they are likely willing to pay at least a bit more. By contrast, because a firm's surge price approximates the maximum that consumers are willing to pay for additional output (actually, the surge price will tend to be a bit above consumers' maximum willingness to pay for additional output, because demand slopes downward), surge prices beckon into the market not only those competitors that have costs slightly in excess of the firm's, but also competitors that have costs much in excess of the firm's. Indeed, surge prices beckon into the market all firms that can possibly satisfy the excess demand, not just those that can do so at lowest cost.

The fact that surge pricing beckons more firm sin to the market than

\footnotetext{
${ }^{126}$ See Woodcock, supra note 74, at 55.

${ }^{127}$ See id.

${ }^{128}$ See id.

${ }^{129}$ See id.

${ }^{130}$ See id.

${ }^{131}$ See id.

${ }^{132}$ See id.
} 
does selling out seems to suggest that surge pricing does a better job of calling in the cavalry to satisfy excess demand than does selling out, making surge pricing the better choice for consumers. But surge pricing may not beckon quite as many firms into the market as first appears. In particular, savvy high-cost producers will understand that lower-cost producers will still have a greater incentive than they to enter the market, as lower-cost producers will be able to charge the same near-surge prices as the high-cost producers, but face lower costs. And once lower-cost producers are in the market, their lower costs will allow them to undersell any high-cost producers who enter, denying the high-cost producers any opportunity to earn a profit. So high-cost producers may delay market entry to see whether lower-cost producers appear, leading to much the same result as under the sold out signal, which will tend to beckon only lower-cost producers into the market.

The ambiguity of the surge pricing signal relative to the sell-out signal also suggests that the surge pricing signal is unlikely to draw many more competitors into the market. A high price presents a somewhat more ambiguous signal to other firms that there is excess demand in the market than does information that the firm has sold out. For, as we saw in Section II.F, an unexpected shortfall in demand that forces a firm to suffer losses can nevertheless also cause the firm to raise prices. If a competitor mistakes the price increase for a signal that demand is surging and, as a result, chooses to enter the market, the competitor will make a loss because the competitor will quickly discover that the firm has plenty of excess inventory on hand with which to satisfy demand, allowing it to win a price war with the new entrant. Competitors will therefore hesitate before rushing into a market in response to a price surge. By contrast, selling out sends an unambiguous signal that demand has surged. When demand declines, goods do not sell out; they rot on shelves. Thus a low-cost competitor that observes that a firm's inventory has sold out can enter the market confident that the market contains buyers whom the firm is unable to satisfy at any price - at least so long as the competitor enters before the firm can ramp up output.

Even if surge pricing does manage to call more producers into the market than does selling out, consumers may still not end up better off as a result. For the producers that surge pricing beckons into the market are likely to charge higher prices to consumers than they would if beckoned in by information that the firm has sold out, regardless whether the producers produce at high or low cost. ${ }^{133}$ That is because surge pricing provides an

\footnotetext{
${ }^{133}$ See id.
} 
approximate signal regarding the maximum that consumers are willing to pay for the satisfaction of their excess demand, granting producers a crucial piece of information regarding the maximum prices that they can charge. ${ }^{134}$ Whether their costs are low or high, producers will use this information to charge consumers the highest possible prices to satisfy consumers' excess demand, unless consumers are fortunate enough to be in a market in which multiple firms are able to enter the market in response to the signal at the same time and competition between them keeps their prices down. But that is not a foregone conclusion in the context of a demand surge that has taken the market by surprise. ${ }^{135}$

Indeed, if producers beckoned into the market are unable to sell all of their inventory at the high prices they charge, they or their competitors will respond by selling at slightly lower prices. If they or their competitors fail to clear their inventory at the lower prices, they will again cut their prices. So the excess demand will be satisfied in a way that approximates perfect price discrimination, with price stepping down as demand steps down. Each consumer will therefore pay an approximation of the consumer's maximum willingness to pay and will enjoy little or no surplus, as Figure 11 approximately depicts. ${ }^{136}$ In that figure, the successive entry of additional firms into the market steps prices down until the part of the excess demand that the market can profitably satisfy is satisfied. The prices charged by these firms are so high that consumer surplus is limited to the series of relatively small, gray rectangles that remain above the steps but below the demand line. In broadcasting to the market an approximation of the maximum that consumers are willing to pay for the satisfaction of their excess demand, surge pricing deprives consumers of a bargaining advantage that every trader holds dear: the ability to hide one's reservation price. ${ }^{137}$ Stripped of this defense consumers are vulnerable to exploitation by firms. ${ }^{138}$

By contrast, the sold out signal tells producers only that there is excess

\footnotetext{
134 See Ramsi A. Woodcock, Personalized Pricing as Monopolization, 51 ConN. L. REV. 311, 324 (2019).

135 See id. at 331.

${ }^{136}$ See VARIAN, supra note 34, at 445 ("Under . . perfect price discrimination, each unit of the good is sold to the individual who values it most highly, at the maximum price that this individual is willing to pay for it.").

${ }^{137}$ See San Bolkan \& Alan K. Goodboy, Negotiating in Distributive Bargaining Scenarios: The Effect of Sharing One's Alternative, COMM'CN STUD. 1 (2021) (finding via experiment that disclosure of reservation prices causes buyers to pay more).

${ }^{138}$ See id. (finding via experiment that disclosure of reservation prices causes buyers to pay more).
} 
demand at the original, pre-surge price, but not how much consumers are willing to pay for that excess demand to be satisfied. ${ }^{139}$ As a result, only firms that have costs that are close to the pre-surge price will initially consider entering the market, and when they do, they will enter at a price that is close to the original pre-surge price, and to their own costs, rather than close to the maximum that consumers are willing to pay. ${ }^{140}$ Moreover, it should not be supposed that high-cost producers will never enter the market in response to a sold out signal. If the low-cost producers that enter the market prove incapable of fully satisfying the excess demand, then the sold out signal will persist, but now at a higher price, for the low-cost sellers that enter nevertheless have higher costs than the firm that sold out, ${ }^{141}$ and so they will necessarily have sold their output at a price above the pre-surge price. The message that these low-cost entrants have themselves sold out at higher prices will beckon producers with the nextlowest costs into the market. This will persist until demand is satisfied or the highest-cost producers have been drawn into the market. Thus even the sold-out signal is capable of drawing both high and low cost producers into the market, but, unlike the surge price signal, the sold out signal draws them in starting with the lowest-cost and lowest-priced and ending with the highest-cost and highest-priced, which is a progression that both minimizes production costs and so maximizes efficiency and also maximizes consumers welfare, by keeping prices as close to costs as possible. Because low-cost, low-price entry happens first in response to a sold out signal, a sold out signal leaves consumers with a larger share of the surplus generated by satisfying the excess demand. Figure 12 shows the additional surplus enjoyed by consumers relative to surge pricing with the sort of stepped-down, price-signaled entry depicted in Figure 11.

\footnotetext{
${ }^{139}$ See Woodcock, supra note 74, at 55.

140 See id.

${ }^{141}$ Otherwise, they would not have had to be induced to enter the market through the soldout signal.
} 


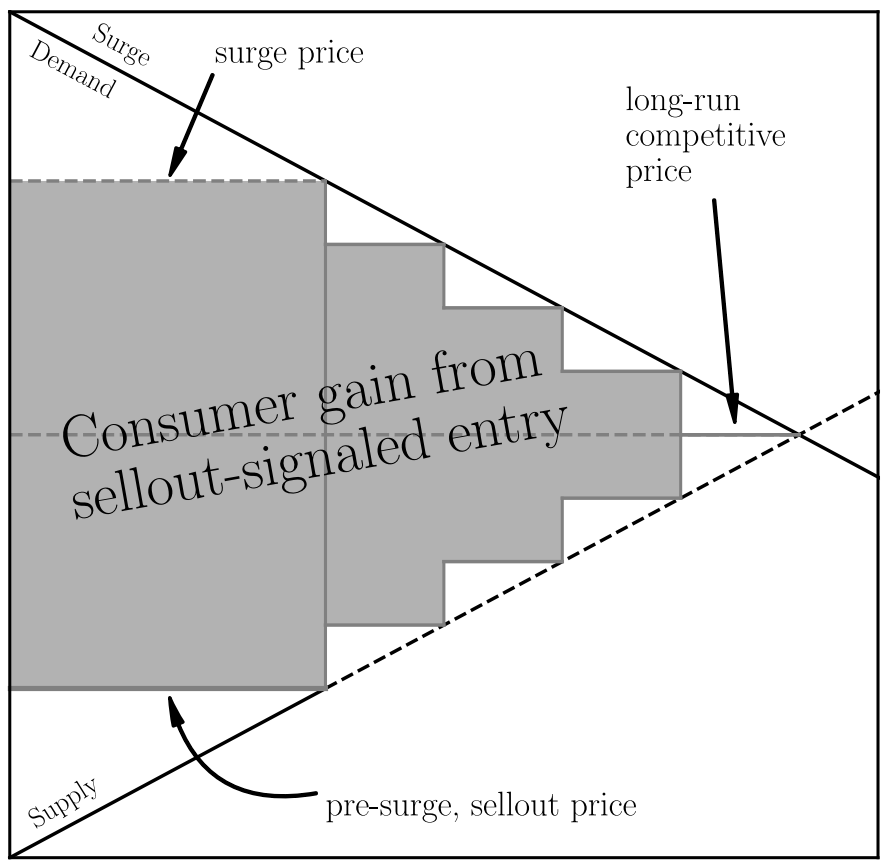

Figure 12

Indeed, the sell-out signal causes market entry in response to the surge to follow the price and cost trajectory that a competitive market would follow in ramping up output in response to a demand surge, because in a competitive market, price follows the intersection of supply and demand as the demand curve marches up the supply curve. Thus, in a competitive market, as in a market governed by a sell-out signal, the lowest-cost producers are drawn into the market first and the highest-cost producers last. ${ }^{142}$

The Internet is also making it just as easy for competitors to observe the signal sent by selling out as to observe the signal sent by high prices. Before the information age a competitor was more likely to observe a higher price than the fact that a good had sold out, because sellers advertise price information, but not a lack of inventory. Today, any competitor can log into a firm's website to learn that a good has sold out - or better yet, can scrape websites for sold out products in order to identify market opportunities. ${ }^{143}$

\footnotetext{
142 See Woodcock, supra note 74, at 55.

${ }^{143}$ Cf. Ramsi A. Woodcock, The Obsolescence of Advertising in the Information Age, 127 YALE L.J. 2270, 2299 (2018) (making the related argument that the Internet has made all the product information that a consumer could ever need freely available online).
} 
For all these reasons, there is no basis for supposing that the surge-price signal makes consumers better off than the sold-out signal, and indeed some reason to suppose that the sold-out signal is better for consumers. It follows that signaling arguments are no objection to prohibiting surge pricing.

\section{B. Surge Pricing Involves No Waiting}

Fifteen years ago, before the spread of surge pricing, there would have been another, far more powerful, argument for the superiority of surge pricing over selling out. For back then selling out brought with it terrible dislocations not associated with high prices, particularly the burden of waiting in physical lines. ${ }^{144}$ To allow the good to sell out meant putting buyers to the trouble of coming down to the store only to find that the inventory is gone, or to the trouble of changing plans to get to the store quicker before the inventory goes, or to the trouble of joining a crowd swollen with buyers all concerned that they will be left unsatisfied, a crowd that might overwhelm, by its size, the ability of the store to process orders quickly. All of these dislocations are wasteful of time that could be spent on productive activities. They made selling out a socially costly signal. ${ }^{145} \mathrm{By}$ contrast, the charging of high prices creates less dislocation: the firm announces a higher price and, before the good starts to sell at all, much less sell out, buyers sort themselves into two groups: those who can afford to buy at the new price and those who cannot. ${ }^{146}$ Those who can afford to buy go down to the store to buy and those who cannot afford to buy do not. ${ }^{147}$ There is no waste of time. Before the information age, high prices solved the allocation problem in the time it took to transmit price information, rather than in the time it took for a customer physically to visit a store, or to wait therein, giving high prices a distinct advantage as a rationing mechanism.

Of course, a price signal can sort consumers before they go down to the store only if consumers actually receive notice of the firm's change in price. If they do not, then surge pricing can still create some of the dislocation associated with selling out. The customer who comes down to the store only to learn that a good is now too expensive to buy is subject to as much

\footnotetext{
144 See Cross, supra note 51, at 293-94.

145 See Barzel, supra note 5, at 73; Robert T. Deacon \& Jon Sonstelie, Rationing by Waiting and the Value of Time: Results from a Natural Experiment, 93 J. POL. ECON. 627, 627-28 (1985); Deacon \& Sonstelie, supra note 165, at 180; see also Cotton M. Lindsay \& Bernard Feigenbaum, Rationing by Waiting Lists, 74 AM. ECON. REV. 404, 404 (1984).

146 See VARIAN, supra note 34, at 7.

${ }^{147}$ See id.
} 
inconvenience as the one who comes down to the store only to learn that the good has sold out. And unexpected price increases upset plans to the same extent as unexpected shortages in supply. But even an uncommunicated surge in prices will not lead to lines. Consumers who come down to the store only to find that prices are too high leave; they do not wait in lines. And firms have an incentive to disseminate information about high prices widely, because, unlike the information that the firm has sold out, high prices generate economic profits. ${ }^{148}$ Thus, before the information age, signaling with price had a distinct advantage.

Today, that advantage is gone, at least with respect to goods that can be purchased online, including those that can be purchased online for in-store pickup only. For today few firms can avoid telling the Internet when a good has sold out and once that information is publicly available, all of the dislocations associated with selling out disappear. ${ }^{149}$ Firms sell online and, unless they wish to discontinue a product, marketing requires that they maintain product pages when goods are temporarily out of stock; but to do that, those pages must make clear to customers who reach them that there is no inventory on hand to sell. With this information displayed online, no customer today need go down to a physical store in order to learn that a product is unavailable. He can simply log into the seller's website and either buy or face the sold-out sign. ${ }^{150}$ Every time a consumer logs into an ecommerce website only to find a "sold out" sign, the consumer has in effect waited on an instantaneously-clearing line. ${ }^{151}$ The time required to learn that a good has sold out has fallen to the same amount of time required to learn that a price has risen-the time required to communicate - eliminating the advantage of high prices as a rationing mechanism. ${ }^{152}$ Economists once characterized selling out as "rationing by

\footnotetext{
${ }^{148}$ See supra Section II.B.

149 See Woodcock, The Economics of Shortages, supra note 33; Woodcock, The Hidden Shortages of the Market Economy, supra note 33; Woodcock, supra note 74, at 55.

${ }^{150}$ See Woodcock, supra note 74, at 55.

${ }^{151}$ See id.

152 To be sure, surge price information still arrives earlier than the information that a good has sold out, because of course things must have prices before they can sell at all, and that makes price signaling still somewhat quicker. But this may merely compensate for the flaw in price signaling, discussed in Section III.A, that the price signal is more ambiguous regarding whether demand is surging than is information that the good has sold out. Thus price signaling may be slower to beckon firms into the market than is selling out, because the price signal is ambiguous, but price signaling may be quicker at beckoning firms into the market than is selling out, because price information necessarily reaches consumers faster than does the information that a firm has sold out. The net effect of these two opposed tendencies may be zero.
} 
waiting;" today it is merely rationing by antecedence. ${ }^{153}$ And the concomitant ability to purchase goods online means that no customer today need rush down to a physical store for fear that a product might sell out. And no crowd of customers need ever overwhelm the ability of a physical store to process orders quickly. The seller's computer can process thousands of order requests per second, so order processing capacity, the bottleneck that drove pre-information-age lines, is gone other than for the very largest crowds.

The newfound efficiency of the queue is one of the quieter revolutions of the information age. But it is everywhere, even in Uber, which seems to sell out-giving users a "no drivers available" message-as often as it engages in surge pricing. ${ }^{154}$ Travelers once waited in line at airport taxi stands to determine whether they would be able to take a cab home. Now they $\log$ into Uber and either book a ride or learn immediately that there are no cars available in the area. ${ }^{155}$ One used to wait in line for groceries during natural disasters. No longer. Today one logs into a supermarket website and arranges for curbside pickup. ${ }^{156}$ One either finds an available timeslot or one does not; there is no wait involved. ${ }^{157}$ To find out whether a good is sold out on Amazon, one spends no more than the seconds it takes to visit the retailer's website. ${ }^{158}$ The closest equivalent to the line today is the website refresh that is sometimes required when trying to get tickets to a hot sporting event or concert. ${ }^{159}$ But that is nothing like waiting in line for hours at the ticket window. Even the famous Black Friday lines for Thanksgiving sales have gone virtual, and so clear instantaneously. ${ }^{160}$

\footnotetext{
153 See Barzel, supra note 145, at 73.

154 See Uber No Cars Available (Why the Error and How to Fix) - RIDE FAQs, https://ridefaqs.com/uber-no-cars-available/.

155 See I Can't Request a Ride, UBER, https://help.uber.com/riders/article/i-cant-request-aride (last visited Aug. 2, 2021).

156 See Nicole Lee, Online Grocery Deliveries Are Facing an Unprecedented Stress Test, ENGADGET (Mar. 30, 2020), https://www.engadget.com/2020-03-30-coronavirus-onlinegrocery-delivery.html [https://perma.cc/JP4W-JCWP].

157 See Nicole Lee, Online Grocery Deliveries Are Facing an Unprecedented Stress Test, ENGADGET (Mar. 30, 2020), https://www.engadget.com/2020-03-30-coronavirus-onlinegrocery-delivery.html [https://perma.cc/JP4W-JCWP].

158 See Suresh Kotha \& Sandip Basu, Amazon and eBay: Online Retailers as Market Makers, in THE MARKet MAKERs: How RETAILERS ARE RESHAPING THE GLOBAL ECONOMY 155, 165 (Gary G. Hamilton et al. eds., 2011).

159 See Aaron Brown, How to Get Those Concert and Gig Tickets that Sell out in Seconds, EXPRESS.CO.UK, https://www.express.co.uk/life-style/science-technology/663433/How-toConcert-Gig-Tickets-Easy-Auto-Refresh-Sell-Out (last visited Jul. 31, 2021).

160 See Kim Bhasin et al., U.S. Holiday Sales Are Booming, Just Not in Stores, BLOOMBERG.COM (Dec. 1, 2020), https://www.bloomberg.com/news/articles/2020-12-
} 
Of course, many Internet users do find themselves waiting in lines in the sense that they sometimes find a product to be sold out and must wait for the product to become available again. ${ }^{161}$ But this does not suggest that surge pricing remains a better way to ration access to goods in short supply. Regardless what mechanism a firm uses to ration, whether a price mechanism or selling out, those who are not granted access through the rationing mechanism must wait for additional supply to arrive. Under a price mechanism, those who cannot afford the high price must do the waiting. ${ }^{162}$ Under a regime of selling out, those who fail to buy first must do the waiting. These will likely be different groups of people, but some group must wait. Because, thanks to the information age, it takes about as long for a buyer to use the Internet to learn that a price has gone up as it takes for a buyer to use the Internet to learn that a product has sold out, today no one need wait long for the rationing process itself-whether based on willingness to pay or antecedence - to be completed and limited inventories to be distributed to those who are lucky enough to have a right to buy the product under the prevailing rationing process. That process takes the time required for an Internet search in both cases. The irony of the information age is that at the same time that it has made it possible for firms to engage in surge pricing-thereby making instantaneous price-based rationing possible - it has also eliminated the dislocation associated with rationing based on place in line, thereby erasing the efficiency advantage of the price mechanism. ${ }^{163}$

The efficiency of the queue in the information age should dispel any concerns that embrace of selling out in the information age will lead to a Soviet-style world of lines-around-the-block to access necessities. ${ }^{164}$ There is also an important difference between the cause of lines in the Soviet Union and the unexpected surge in demand that forces a firm to ration by selling out. Lines were long in the Soviet Union not only because there was

01/black-friday-shopping-moves-online-for-covid-could-be-a-record-in-u-s.

161 See Peter S. Goodman \& Niraj Chokshi, How the World Ran Out of Everything, N.Y. TIMES (Jun. 1, 2021), https://www.nytimes.com/2021/06/01/business/coronavirus-globalshortages.html.

162 See VARIAN, supra note 34, at 7.

${ }^{163}$ Cf. Ramsi A. Woodcock, The Obsolescence of Advertising in the Information Age, 127 YALE L.J. 2270, 2274 (2018) (discussing the other irony of the information age that it both enabled advertisers to target advertising with greater accuracy than ever before and made advertising obsolete by allowing consumers to obtain virtually all product information for free over the Internet).

164 See Kornai, The Socialist System: The Political ECONOMY of Communism 22845 (1992). 
no information technology to allow people to shop from home but, more importantly, because the Soviet Union subsidized prices, meaning that prices were below cost. ${ }^{165}$ In the Soviet Union, shortages arose because the government pushed prices below the capacity of producers to satisfy demand, and kept them there permanently, so that shortages were not the temporary consequence of an unexpected surge in demand, but rather a permanent consequence of long-term government policy. ${ }^{166}$ It was not unexpected surges in demand, but rather expected excesses in demand relative to supply at below-cost prices, that created shortages and lines in the Soviet Union. ${ }^{167}$ In the context addressed in this Article, the firm retains the power to choose its own price, and a firm will always choose a price that covers its costs. As a result, in the context addressed in this Article, shortages exist only because demand has surged unexpectedly, not because, as in the Soviet Union, planners have forced firms to choose below-cost prices that cause even expected levels of demand to outstrip supply.

Because, in the context addressed in this Article, firms retain the power to charge prices that cover their costs, there is also no reason to associate selling out in this context with reduced incentives to invest, as one reasonably could with respect to the kind of selling out that took place in the Soviet Union. ${ }^{168}$ Investors in the Soviet Union could expect to be compelled to charge below-cost prices, so they did not invest. Investors who sell out at prices that cover their costs in response to an unexpected surge in demand cover their costs and continue to invest.

Unlike the shortages of the Soviet Union, the shortages at issue in this Article are shortages that necessarily appear in any economy, because they result not from poor planning but from the inability fully to predict the future. ${ }^{169}$ These shortages are perhaps more often hidden in capitalist economies, because they can be covered up with price increases designed to ration access to the good in short supply using price instead of the "sold out" notice, but they are just as real and pervasive as they would be were

\footnotetext{
165 See id. ("Unless lucky, [the shopping of a woman in a socialist system] is not a single action but a process, a sequence of decisions .... [E]vent 1, beef is available, but customers must queue for it. This is a familiar occurrence; under classical socialism customers very often have to queue. For some goods there is an actual, 'physical' queue at the counter or outside the store ... [T] [Te good she seeks may not be available at all, either immediately or after queuing. In that case she must choose from a further set of alternatives."').

166 See id.; Lindsay \& Feigenbaum, supra note 145 , at 405.

167 See KORNAI, supra note 164, at 228-45.

168 See id.

${ }^{169}$ See Woodcock, The Hidden Shortages of the Market Economy, supra note 33.
} 
rationing always to be implemented through selling out. ${ }^{170}$ Thanks to the Internet, these shortages can now be addressed without either the regressive distributive effects of rationing with price, or the pain of waiting. ${ }^{171}$

Not only does selling out no longer inflict any more costs of waiting than does rationing with high prices, but it may even have a cost advantage relative to surge pricing because, unlike surge pricing, selling out costs nothing to implement. To sell out of a product requires no more than the cost of listing the product as sold out on its product webpage. To engage in surge pricing requires the acquisition of the information technologies required to adjust prices quickly in response to changes in demand. ${ }^{172}$ In particular, it requires investment in the acquisition of a piece of information that a firm that sells out does not require: the price that will actually attract only so much demand as existing supply can satisfy. ${ }^{173}$ If the firm chooses a price that is too low, the firm will leave money on the table, and if the firm chooses a price that is too high, the firm could potentially make a loss. ${ }^{174}$ But to find the right price, the firm must know enough about the distribution of willingness to pay among consumers to pick the cutoff price that separates the wealthy few who should take under this rationing system from those who should not. ${ }^{175}$ That requires data and processing power not required to sell out. ${ }^{176}$ Indeed, it is an indication of the relative costlessness of sellout that surge pricing often devolves into selling out because of the difficulty of surge pricing effectively. A firm trying to engage in surge pricing while minimizing information costs may start to sell at a very high price and then lower price bit by bit until all inventory has sold, but unless those increments are very small, and all potential buyers are ready to purchase at the same time, the firm may overshoot, reducing price by too far, leading to an excess of demand that must be resolved in the end by selling out. ${ }^{177}$ Thus the additional information requirement for surge pricing

\footnotetext{
${ }^{170}$ See id.

${ }^{171}$ See Woodcock, supra note 74, at 55.

172 See Lynn DeLain \& Edward O'Meara, Building a Business Case for Revenue Management, 2 J. REVENUE \& PRICING MGMT. 368, 370 (2004) (estimating that setting up a "revenue management" system costs between $\$ 3$ million and $\$ 10$ million).

173 See Steven Orla Kimbrough, Agents, Games, and Evolution: Strategies at WORK AND PLAY 193-98 (2011).

${ }^{174}$ See id.

175 See id. Part of this sentence appears verbatim in Woodcock, The Efficient Queue and the Case Against Dynamic Pricing, supra note 1, at 1792. For why, see supra note 1.

176 See DeLain \& O’Meara, supra note 172, at 370.

177 See KIMBROUGH, supra note 173, at 193-98. Part of this sentence and the next appears verbatim in Woodcock, The Efficient Queue and the Case Against Dynamic Pricing, supra note 1 , at 1792 . For why, see supra note 1.
} 
causes surge pricing to shade into the simpler system of rationing based on antecedence. Another way in which surge pricing can shade into selling out will be considered in the next Section.

\section{Surge Pricing Allocates}

The third major objection to prohibiting surge pricing is that surge pricing allocates products to those who value them the most. ${ }^{178}$ Because economies generate the most surplus when they allocate goods to those who place the highest value on them, it follows, the argument goes, that surge pricing is efficient and therefore should not be banned. ${ }^{179}$

One problem with this argument is that antitrust is not concerned with efficiency - with maximizing total surplus - but rather with the welfare of consumers - with maximizing consumers' share of the surplus. ${ }^{180}$ Whether surge pricing does good and should be protected therefore depends not upon whether surge pricing increases the size of the pie, but upon whether surge pricing increases the size of consumers' slice of the pie. ${ }^{181}$ The fact that surge pricing increases the size of the pie by raising prices, which is a way of redistributing wealth from consumers to firms, implies that surge pricing transfers at least some of any increase in total surplus that it brings about to firms. If the amount transferred is large enough, it is possible that consumers might be better off under a less-perfectly allocative rationing system that leaves them a larger share of whatever smaller increase in total surplus that the system brings about. ${ }^{182}$

A comparison of the grey areas in Figure 13 and Figure 14 provides an example. In Figure 13, the surge price allocates the product to the consumers who have the highest willingness to pay (those at the highest point of the demand line). ${ }^{183}$ However, most of the value created thereby is appropriated by the firm through the high surge price, leaving only the small grey triangle of surplus for consumers. By contrast, in Figure 14, sell-

178 See VARIAN, supra note 1 , at 15-17.

179 See BAUMOL, supra note 73, at 498.

${ }^{180}$ See Kirkwood \& Lande, supra note 25, at 192.

${ }^{181}$ See id.

182 See VARIAN, supra note 178, at 249-50.

183 The practice of measuring surplus as the area under a demand line assumes that willingness to pay — which is represented by the demand line — is a perfect proxy for value. See BAUMOL, supra note 73 , at 498 . It is for this reason that the graphical treatment in Figure 12 and Figure 13 is appropriate to examination of the consumer welfare effects surge pricing under the assumption that surge pricing does a perfect job of allocating products to those who value them the most. 
out pricing enables consumers with the lowest willingness to pay to obtain the product by executing their purchases before the high willingness to pay consumers are able to do so. If we assume that willingness to pay is a good proxy for the value a consumer places on a good, then the sell-out pricing depicted in Figure 14 is less efficient than the surge pricing depicted in Figure 13. The total area above the supply line and below the demand line of the consumers who buy in Figure 13-which gives the total surplus created by surge pricing - is smaller than the total area above the supply line and below the demand line of the consumers who buy in Figure 14, which gives the total surplus created by sell-out pricing. But, even so, the low sell-out price in Figure 14 ends up creating more surplus for consumers - represented by the large grey trapezoid - than does the surge price in Figure 13, which creates only the small grey triangle of surplus for consumers. So sell-out pricing can make consumers better off even if it does a worse job than surge pricing at allocating goods to those who value them the most.

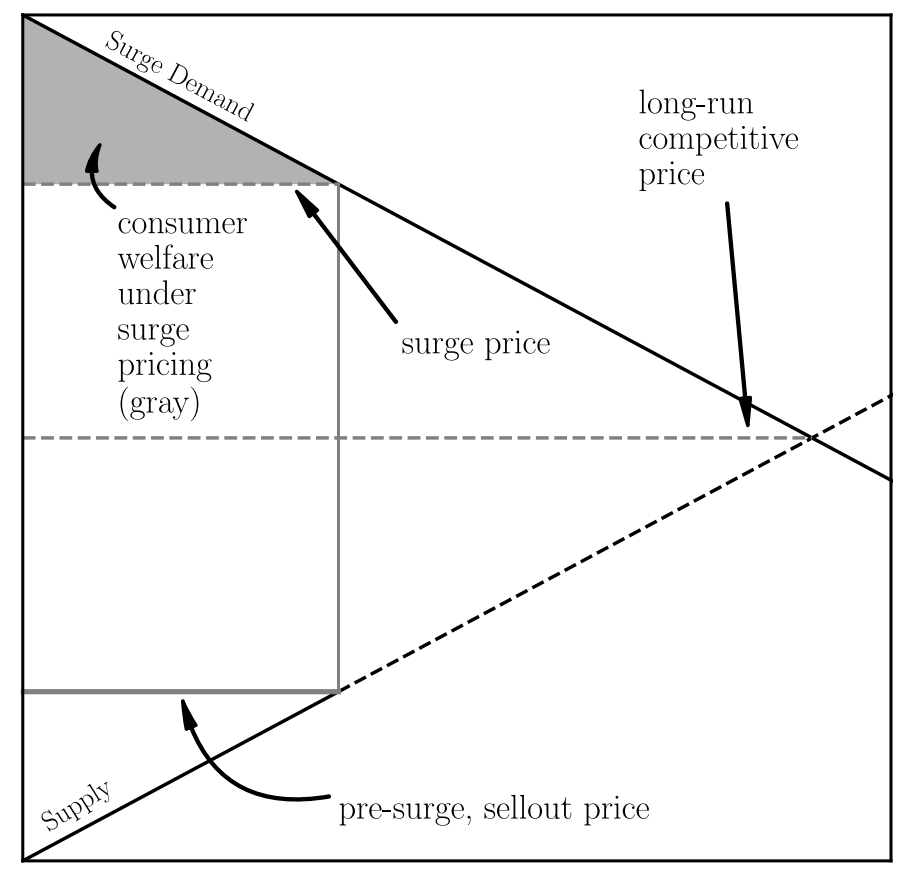

Figure 13 


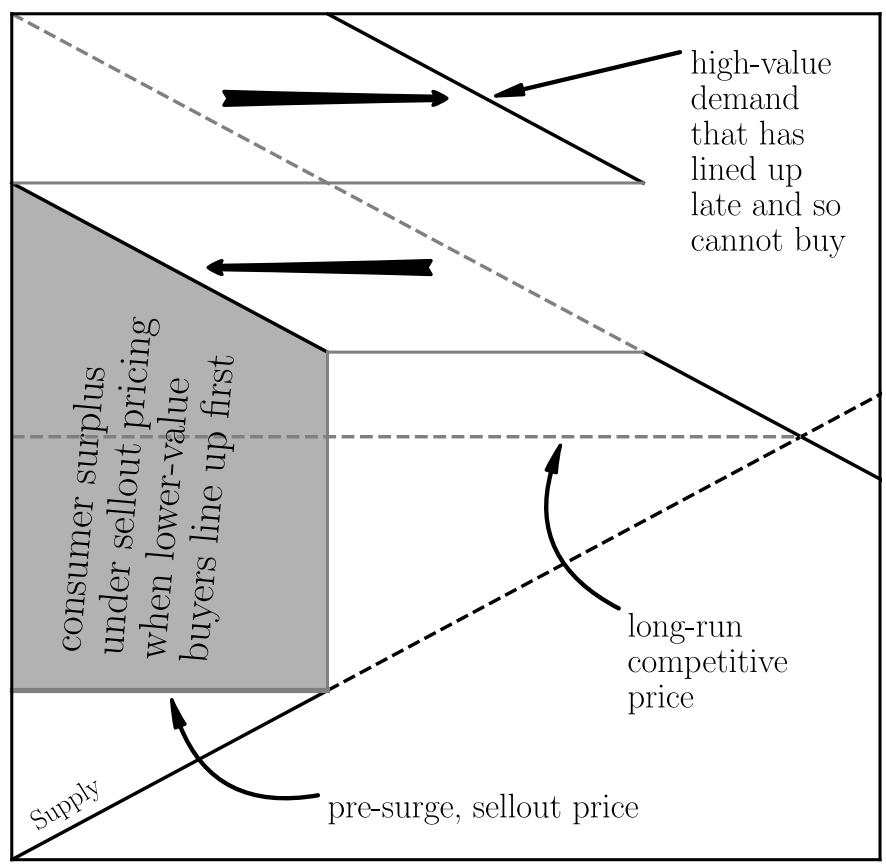

Figure 14

Another problem with the allocation objection is that high prices do not, in fact, do a perfect job of allocating products to those who value them the most, and, more importantly, there is no basis for supposing that selling out does any worse of a job at allocating products than do high prices. High prices allocate effectively only to the extent that willingness to pay, which is the criterion according to which high prices determine who can buy and who cannot, is a good proxy for value. ${ }^{184}$ It certainly is reasonable to suppose that some people are willing to pay more for a product because they place a higher value on it than do those who are willing to pay less. ${ }^{185}$ But it is equally reasonable to suppose that some people are willing to pay more for a product because they are rich, rather than because they place a higher value on the product than do those who are willing to pay less for it. ${ }^{186}$ Money has less value to the rich than it does to the poor, because the rich have more of it, and so it follows that a rich man may be willing to pay more for a product than a poor man even if the poor man places a higher

\footnotetext{
${ }^{184}$ See VARIAN, supra note 1 , at 15-17.

185 See VARIAN, supra note 1 , at 15-17.

186 See SILBERBERG, supra note 153, at 396-402; VARIAN, supra note 1, at 141-42; BAUMOL, ECONOMIC THEORY, supra note 63, at 498-500.
} 
value on the product. ${ }^{187} \mathrm{We}$ understand this point so intuitively that in daily life we are as likely to say that we do not wish to buy such and such a thing because it is too expensive (reflecting our unwillingness to pay for it) as we are to say that we do not wish to buy it because we cannot afford the thing, suggesting that financial constraints are preventing us from fully expressing the level of value we place on the good through our willingness to pay for it. ${ }^{188}$ It follows that price may well allocate as much based on wealth as it does based on actual value.

Selling out, which employs antecedence as its proxy for value, is a similarly flawed means of allocating goods to those who value them the most. ${ }^{189}$ It is certainly reasonable to suppose that some of those who arrive first to purchase a product do so because they place a higher value on the product than do those who arrive later. And it is easy to imagine that some of those might be buyers who would otherwise have been priced out of the market by the use of high prices as a rationing device. But, as in the case of rationing by high prices, it is equally reasonable to suppose that some of those who arrive first do not actually place a higher value on the good than do those who arrive later. ${ }^{190}$ These might be early risers, or the fleet of foot, or those who are handy at computers, but who place no special value on the good. ${ }^{191}$ And they might well beat out those who both place a higher value on the good and are wealthier, and who therefore would have been able to gain access to the product under a price-based rationing regime. ${ }^{192}$

If both proxies for value - willingness to pay and place in line-are flawed, then which is at least better at allocating products to those who value them the most? The answer is unclear, and so allocative efficiency cannot serve as a basis for preferring surge pricing over selling out. ${ }^{193}$

\section{Surge Pricing Is Inevitable}

\footnotetext{
187 See BAUMOL, ECONOMIC THEORY, supra note 63, at 501.

${ }^{188}$ See id. at 190-91. One might argue that if the economy doles out wealth as a reward to those who have worked hard to make society better, then any allocative losses to consumers associated with rationing through high prices might be more than offset by the incentive effect of wealth on the productivity of the rich and those who aspire to be rich. It is far from obvious, however, that most wealth is gained as part of such a reward mechanism.

189 See Barzel, supra note 145, at 73.

190 See id. (arguing that because the poor have a lower "time-cost" they have an advantage in a queue-based system of rationing).

191 See Eric Budish et al., The High-Frequency Trading Arms Race: Frequent Batch Auctions as a Market Design Response, 130 Q. J. ECON. 1547, 1548-49 (2015).

192 See Barzel, supra note 145, at 73.

${ }^{193}$ See Woodcock, supra note 74, at 52.
} 
It is sometimes argued that rationing with price is preferable to selling out because selling out inevitably devolves into rationing with price, making rationing with price inevitable whether it is prohibited or not. ${ }^{194}$ The rich will always buy their way to the head of the line, the argument goes, so all lines collapse into methods of rationing based on willingness to pay. ${ }^{195}$ Our problem with this argument is that if it were really true, there would be no need to deploy it in defense of rationing with price, for selling out would produce the same result. Prohibiting surge pricing would change the distribution of wealth, as the rich would pay their high prices to those who manage to get in line first, not to the seller of the good. But the same group of highest-willingness-to-pay buyers would get access to the good as would get access were the seller to engage in surge pricing. ${ }^{196}$ If selling out achieves the same allocative result as surge pricing, there is no reason to insist that firms be permitted directly to engage in surge pricing.

Another, more profound, problem with this argument is that there is no more reason to suppose that money undermines queues than there is to suppose that queues undermine money. One can undermine a queue and the validity of place in line as an independent proxy for value by buying one's way to the head of the line, but one can undermine the money system and the validity of willingness to pay as an independent proxy for value by using place in line to get the money that determines one's willingness to pay. The person who gets in line first in the morning at the temp agency, or is first to invest in plastics, or is first to redevelop the neighborhood, gets more money than do others, and thereby increases his willingness to pay for goods, outbidding others for them. ${ }^{197}$ Indeed, to the extent that business

\footnotetext{
${ }^{194}$ See Mankiw, supra note 38 ("High prices are a natural reflection of great demand and scant supply. In a free market, in which private individuals can engage in mutually advantageous gains from trade, they are inevitable until demand subsides or supply expands.").

195 See Stewart, supra note 53 ("If you keep prices low, people will buy tickets and resell them on the secondary market. Someone is going to pay a market-clearing price, no matter how high."); Deacon Robert T. \& Sonstelie Jon, supra note 38, at 179-80; W. KIP VISCUSI ET AL., ECONOMICS OF REGULATION AND ANTITRUST 684-87 (4th ed. 2005).

196 That would not discourage production, as the seller of the good sells at the pre-surge, presumably at-cost, price to those in the line. Those buying their way to the head of the line pay the premium that they would have paid to the seller had the seller engaged in surge pricing to those in the line instead, in exchange for their access to the good.

${ }^{197}$ See F. M. Scherer, First Mover Advantages and Optimal Patent Protection, 40 J. TECH. TRANSFER 559, 563-64 (2015) ("[T]he first to market a new product often engrains in the minds of consumers an 'image' of superiority-that is, a product differentiation advantage-allowing it to retain a substantial market share while charging prices appreciably higher than those realizable by latecomers.”); F.M. SCHERER \& DAVID ROSS,
} 
success can be attributed to being first, all attempts to use price to ration collapse into rationing based on place in line. ${ }^{198}$ To be sure, this collapse is not quite the same as the way rationing based on place in line can be said to collapse into price rationing, for those who acquire their money by being first do not usually do so with the goal of acquiring a specific good. But those who buy their way to the head of a line undermine a specific queue to acquire a specific product. The effect is, however, the same: the power of one proxy for value is undermined by another. The man who strives to be the first to invent a product that will make him rich might not do so with a specific good in mind, but he may well do it with all goods in mind: he might want to be able to outbid everyone for everything. And so it may fairly be said that in becoming rich by being first he undermines every attempt to ration with price in every market. ${ }^{199}$

The reason that rationing with lines and rationing with prices can shade into each other is that both being rich and being first are powerful means of gaining access to goods and services, regardless what system is formally in place to control access. Legal rules can be used to prevent a regime built

Industrial MARKet Structure AND ECONOMIC PERFORMANCE 626-30 (3d ed. 1990) ("[B]eing first to bring a new product onto the market, with or without patent protection, often confers a substantial reputational advantage over imitators, permitting the innovator to maintain elevated prices while defending a sizeable market share.").

198 See Scherer, supra note 109, at 560-61; SCHERER \& ROSS, supra note 39, at 626-30.

199 It is certainly true that striving to be first in order to be rich sometimes creates an incentive to productive activity that does not exist when one buys a place at the head of a line. A man who invents a new drug faster than anyone else, to the end of becoming rich and thereby undermining the money system, confers an incidental benefit on society that a man who pays someone to hold a parking spot for him, thereby to undermine the queue system, does not. See Eliana Dockterman, App for Selling Public Parking Spots Suspends Service in San Francisco, TIME (Jul. 11, 2014), http://time.com/2974647/monkeyparkingparking-space-app-suspended [https://perma.cc/J7LM-4LDU]. And so the undermining of the money system with queuing is more productive than the undermining of the queue system with money. The question, however, is whether the productivity benefits associated with having a price-based rationing system that is undermined by productive behavior aimed at being first offsets the distributive harm to consumers of paying higher prices under such a price-based rationing system, relative to a queue-based system. $C f$. supra note 188.

Those productivity benefits are necessarily limited, because under a queue-based system there remains plenty of incentive to engage in productive activity. For in order to be admitted to the queue in the first place, one must be able to afford the cost of production of the product in question. That is, one must be able to pay the pre-surge price. Under a queue-based system there remains, therefore, a powerful incentive to productive activity aimed at generating the funds with which to enter the queue. Whatever additional incentive to productive activity the undermining of a price-based system creates is therefore merely additional to the incentive created by queue-based systems. 
around one from being undermined by the other, but enforcement will never be perfect. Buying a privileged place in line can be banned. ${ }^{200}$ And the exploitation of first-mover advantages in business can be prohibited, as, in a sense, a rule against surge pricing, predicated as surge pricing is on a firm's ability to sell inventory before others can ramp up production, itself is. But some will escape these prohibitions. All that matters, however, for purposes of deciding whether to prohibit surge pricing is that there is no reason to suppose that such prohibitions will be any more effective at preventing rationing with prices from becoming rationing with lines than it will be at preventing rationing with lines from becoming rationing with prices.

\section{E. The Coming Alternatives to Selling Out}

The information age is making it easier for firms directly to identify desire and route supply to satisfy it, and so is likely to give birth to additional approaches to rationing access to goods in short supply. These approaches will be as good at avoiding lines and other dislocations, and as good at allocating goods to those who want them the most, as surge pricing or selling out are today. The emergence of each new form will weaken the argument for surge pricing even further. Consider, for example, the problem of downtown parking, for which surges in demand have traditionally been handled by selling out. Municipal parking meters charge a fixed price for parking and do not raise that price when demand surges, so the inventory of parking spots is effectively rationed based on antecedence: whoever first arrives at the spot parks. This results in terrible dislocation and wastestudies show that $30 \%$ of downtown driving is spent looking for parking spots - that could be avoided either through implementation of surge pricing via parking meters or adoption of an online reservations systemthat is, an efficient queue-for parking spots. ${ }^{201}$

But there is a third way. Imagine that, rather than simply allow users to reserve spots, the online reservations system were to prioritize access to

\footnotetext{
${ }^{200}$ See McFadden, supra note 53, at 428-29.

201 See Paul Barter, Is 30\% of Traffic Actually Searching for Parking?, REINVENTING PARKING (Oct. 7, 2013), https://www.reinventingparking.org/2013/10/is-30-of-trafficactually-searching-for.html [https://perma.cc/43VL-26YS]. A San Francisco startup in fact tried to implement surge pricing for public parking spots before being shut down by the city. See Eliana Dockterman, App for Selling Public Parking Spots Suspends Service in San Francisco, TIME (Jul. 11, 2014), http://time.com/2974647/monkeyparking-parking-spaceapp-suspended [https://perma.cc/J7LM-4LDU]. The app would have undermined San Francisco's queuing system by sending employees to hold spots and then selling the spots at a premium; thus surge pricing would have replaced the queue.
} 
spots based on a user profile, which might include information about the reason for which the user wishes to park downtown, the driver's safety record, and so on. ${ }^{202}$ Someone traveling to access government services and having a clean driver safety record might receive a spot. A joyrider not. This would represent a different approach to rationing, because it would be based neither on willingness to pay nor, entirely, on place in line. But, depending on the quality of the user profiles, such a system might do just as good a job of allocating access to those who need it the most as would either surge pricing or online queuing. Cities might also use such a profilebased system to ration access to congested downtown streets, creating an alternative both to surge pricing (called congestion pricing in this context) and queuing (also called capping the number of vehicles admitted downtown). ${ }^{203}$ Thus surge pricing will become just one among many ways effectively to ration access during shortages.

\section{BROADER APPLICABILITY}

\section{A. Resale, Securities and Commodities Trading, and Price Gouging}

\section{Resale and Securities and Commodities Trading}

The case against surge pricing has broader applicability than might at first appear. It not only applies to consumer products - the context in which it has been developed so far in this Article-but to all products, save those that can be produced as quickly as new prices. ${ }^{204}$ It also applies to the resale of products produced by others so long as resale cannot be executed as quickly as a change in price. The case of "intramarket resellers" who resell products into the same market in which they purchase them is particularly interesting.

In general, intramarket resale should not be profitable because the original seller should be able to exploit any profit opportunities that resellers exploit. But there are exceptions, one of which appears when firms forego profit opportunities during a demand surge by charging sell-out prices rather than surge prices. ${ }^{205}$ The intramarket reseller can then swoop

202 See T. Lin et al., A Survey of Smart Parking Solutions, 18 IEEE TrAnSACTIONS ON INTELLIGENT TRANSPORTATION SYSTEMS 3229, 3229 (2017).

203 See Ramsi Woodcock, Congestion Pricing Is Class Warfare. Here's a Better Idea, OZY, http://www.ozy.com/immodest-proposal/congestion-pricing-is-class-warfare-heresa-better-idea/93503 (last visited Mar. 31, 2019).

${ }^{204}$ See supra note 62.

${ }^{205}$ Outside of the demand surge context, intramarket resale can also be profitable when 
in, buy up the firm's inventory at the low sellout price and then resell it into the same market at surge prices, turning a profit. For consumers, the effect is to transform a market characterized by sellout pricing into one characterized by surge pricing, only now the firm appropriating the profits associated with surge pricing is the reseller, rather than the firm that produced the goods. Ticket scalping is an example. The hit Broadway show Hamilton pledged not fully to exploit its power to charge surge prices, allowing its tickets to sell out instead. But scalpers bought up seats at the below-surge prices and resold them at higher surge prices, frustrating the show's plans. The result was that consumers still paid high prices, but resellers, rather than the show, profited. ${ }^{206}$ Resellers undermine the queue, not by acting as consumers who use money to buy their way to the head of the line, as described in Section III.C, but by buying up the entire inventory and reselling it to the highest bidder.

As the example of ticket scalping suggests, surge pricing by intramarket resellers is a major threat to firms that choose voluntarily to forgo surge pricing themselves. Firms may take that chance out of a sense of moral obligation to consumers, or to avoid alienating consumers by exploiting them during temporary surges in demand. ${ }^{207}$ Or firms may simply wish to invest elsewhere the funds needed to set up a surge pricing system. Whatever the reason, intramarket resale forces firms that want to avoid surge pricing to embrace it lest they fail to cash in on consumer harm that

used to arbitrage a firm's attempt to personalize prices. See Woodcock, supra note 134, at 323, 333-34. Resellers buy up, at low prices, the inventory that the firm sells to some buyers at low personalized prices and then resell it at a slight discount on the high prices that the firm would personalize to other buyers, thereby turning a profit. See id. In contrast to intramarket resale directed at sellout pricing during a surge, which, like all surge pricing, weakens the effects of pre-surge competition, this arbitrage is procompetitive conduct in that it prevents the firm from maintaining high personalized prices and so undermines the entire personalized pricing scheme; the resellers effectively compete with the firm in the sale of inventory to the buyers to whom the firm would target high prices. See id. It follows, I have argued in another article, that attempts by firms to prevent intramarket resale in this context are anticompetitive and violate Section 2 of the Sherman Act. See id.

206 See Mankiw, supra note 38 (arguing that it is a shame that the Broadway show Hamilton did not engage in more vigorous surge pricing, thereby allowing resellers to capture the profits that the show could have earned).

207 See Utpal M. Dholakia, If You're Going to Raise Prices, Tell Customers Why, HARVARD BUSINESS REVIEW (Jun. 29, 2021), https://hbr.org/2021/06/if-youre-going-toraise-prices-tell-customers-why ("When performed poorly, the news [of a price hike] can lead to undesirable outcomes like customer complaints, social media outrage, and even worse, having to walk back the price increase, or losing customers altogether."); Mankiw, supra note 38 (lamenting the fact that, out of apparent respect for its audience, the show Hamilton does not charge the maximum possible surge prices). 
they are no longer able to prevent.

Intramarket resale would also undermine a ban on surge pricing unless it were also banned. Fortunately, intramarket resale that employs surge pricing would be a per se violation of Section 2 of the Sherman Act for the same reasons, discussed in Part II, for which all surge pricing should be a violation. So if one is banned the other must be too. Indeed, the case against intramarket resale is even stronger because there can be no doubt that the surge price is unnecessary to cover production costs if the original producer was willing to sell the inventory to the reseller at the low sellout price. There also can be no doubt that a reseller's price increase is executed faster than the reseller can increase supply, for resellers are incapable of ever increasing their output, much less increasing it at the same speed with which they raise prices. A reseller can acquire its inventory only by purchasing it on the same market in which the reseller sells the inventory. Thus in order for a reseller to bring additional supply to market to satisfy a surge in demand, the reseller must buy more of the good on the same market, effectively increasing the surge in demand (because the reseller's attempt to buy more represents additional demand) to the same extent that the firm seeks to increase supply, and so making no progress toward its goal of offsetting the surge in demand with additional supply. ${ }^{208}$

It follows from this analysis that algorithmic ticket scalping should be per se illegal. Of far greater significance, it follows as well that alogorithmic securities and commodity trading should be per se illegal, at least when the trading is carried out on a single, centralized, exchange. Traders doing business on a centralized exchange are intramarket resellers. Their business model is surge pricing. They buy low and hope that an unexpected surge in demand will allow them to sell high. Or they exploit the failure of a seller to charge surge prices in response to an unexpected surge in demand to buy low and sell high. Indeed, an intramarket reseller's business model can only be surge pricing because the reseller buys the security or commodity at the market price and so the reseller's cost of production, exclusive of any return on its investment, is the pre-surge price itself. It follows that the reseller cannot ${ }^{209}$ generate income unless an

\footnotetext{
208 Thus, a plaintiff in a case against a within-market reseller need only define a relevant market and show that the defendant both buys and sells in that market in order to satisfy the requirement of proof that the defendant can increase price faster than supply. The inability of a reseller to expand supply is unique to the intramarket resale context. By contrast, a firm that buys goods in one market to resell them in another market does expand supply in the destination market by introducing into it goods that had been in the other market.

209 There is one exception: intramarket resellers can generate income by arbitraging an attempt by the original seller to personalize prices. See supra note 205.
} 
unexpected shift in demand makes it possible for the reseller to charge a higher price. $^{210}$ If the demand shift were expected, then the reseller's suppliers would charge a premium to the reseller to appropriate from the reseller any profits that the reseller might otherwise generate from the extra demand. $^{211}$

The radicalism of this result reflects no more than the fact that any income won by serving as a middleman between the same two markets is necessarily redistributive in character, as the middleman produces nothing other than the act of buying low and selling high and hence has no genuine production costs with which to justify any price increases; carrying this out with algorithms only magnifies the redistribution. ${ }^{212}$ Intramarket resale is also known as speculation. ${ }^{213}$ Some argue that speculation has useful allocative or signaling functions, but these arguments have already been dealt with in Part III and will be addressed again in relation to securities and commodities trading in Section IV.B.2. ${ }^{214}$

\footnotetext{
${ }^{210}$ By contrast, the original seller will build a reasonable return on investment into the presurge price that the seller chooses, otherwise the seller would not choose that price. So the original seller does not need an unexpected shift in demand in order to generate income.

${ }^{211}$ See supra Section II.F.

212 This is equally true for intramarket resale that arbitrages personalized pricing. See supra note 205. However, to the extent that such arbitrage undermines attempts to redistribute wealth on a grand scale via personalized pricing, it may be considered a comparatively benign form of intramaket resale.

${ }^{213}$ For more on speculation, see infra Section IV.B.2. For an example of resale within the same market that is not meant to generate a surge profit, see infra note 214.

${ }^{214}$ See, e.g., John F. Barry, The Economics of Outside Information and Rule 10b-5, 129 U. PA. L. REV. 1307, 1316-19 (1981). Another defense of within-market resale not addressed in Part III might be that it shifts risk from producers that are less able to bear it to resellers that may be better able to bear it. A producer might, for example, face the risk that demand might decline unexpectedly, resulting in a loss of $\$ 10$ million, or that demand might increase unexpectedly, resulting in a gain, thanks to surge pricing, of $\$ 10$ million. But a reseller that acquires the producer's inventory and hence its risks of gain and loss might face, overall, no risk after the acquisition because the reseller might also own assets that would appreciate in value by $\$ 10$ million in the event of an unexpected shortfall in demand and depreciate in value by $\$ 10$ million in the event of an unexpected surge in demand, effectively causing the reseller to break even in both eventualities.

This certainly is a socially useful role for a reseller to play and resellers can play it even under a surge pricing ban. Under a ban, resellers remains free to engage in resale so long as they do not engage in surge pricing with respect to the goods that they resell. A producer would still be perfectly free to transfer an inventory that might command a profit of $\$ 10$ million or make a loss of $\$ 10$ million, and resellers would still be perfectly free to acquire that inventory and resell it. But the source of the possible $\$ 10$ million gain could not be surge pricing, at least not algorithmic surge pricing. The prospect of profit might be due instead to the scarcity of the product, which would enable the inventory to generate profits
} 
Surge pricing by intramarket resellers is a particularly pernicious form of surge pricing for two reasons. First, the activity of intramarket resale is itself costly - the trader or scalper incurs administrative costs in buying and selling - but produces nothing other than a redistribution of wealth either from producers to resellers (if producers would have engaged in surge pricing had they not sold to resellers) or from consumers to resellers (if producers would not have engaged in surge pricing had they not sold to resellers). That makes the administrative costs of reselling count as pure economic waste. ${ }^{215}$ Second, one might believe that producers deserve the surge profit more than do intramarket resellers because producers actually produce the product that consumers buy. That is, producers are responsible for creating the value to consumers that ultimately makes consumers willing to pay surge prices. Intramarket resellers are not responsible for that value and so it seems unjust to allow them to appropriate a substantial portion of it. ${ }^{216}$ It is important, however, not to take this argument too far. The surge profits that resellers appropriate are surplus, which by definition is the excess of value created for consumers over the value's cost of production, and so surge profits are not strictly necessary to make producers ready, willing, and able to produce. ${ }^{217}$ It follows that producers do not really need those profits any more than do resellers. But if someone other than consumers is to take the profits, it would seem more just for the firm that created the surplus through productive activities to take them rather than for the firm that merely bought low and sold high to take

even at competitive, pre-surge prices. See Ramsi A. Woodcock, Antimonopolism as a Symptom of American Political Dysfunction (2021), https://papers.ssrn.com/sol3/papers.cfm?abstract_id=3864585. The fact that under a surge pricing ban no reseller would be able to make a profit from surge pricing would not keep resellers from entering the market to perform the risk shifting function, because that function benefits resellers, since inventory flows from firms that are less able to bear risk to those that are better able to do it. In the example, the reseller is able to use the inventory to hedge its risk from other assets; thus the reseller gains and should be willing to engage in resale even absent the opportunity to profit on the resale using surge pricing.

215 See Gordon Tullock, The Welfare Costs of Tariffs, Monopolies, and Theft, 5 ECON. INQUIRY 224, 232 (1967).

${ }^{216}$ By contrast, intermarket resellers do produce something, such as physical transport of goods from one market to the other or information that helps buyers in one market find products in the other. See Donald J. Boudreaux, The Middleman Serves an Essential Economic Function, AIER, https://www.aier.org/article/the-middleman-serves-anessential-economic-function/ (last visited Aug. 12, 2021) ("Wholesalers specialize in transporting goods from around the country, or even the world, and assembling these in accessible, central locations at which retailers' delivery trucks can be loaded."). For this reason, intermarket resale is, in general, a good thing.

217 See BAUMOL, supra note 73, at 593. 
them. $^{218}$

\section{Price Gouging}

The case against surge pricing also sweeps in a great deal of conduct that is currently prohibited by state laws against price gouging, as well as a great deal of conduct that fits a reasonable economic definition of price gouging but which today is not covered by state price gouging laws, so long as the price gouging is implemented with the aid of algorithms. ${ }^{219}$ That is because, apart from the requirement that high prices be implemented through algorithms, my proposed test for surge pricing doubles as a reasonable economic definition of price gouging. ${ }^{220}$ The public hates price gouging precisely because the high prices of which the public complains arise in response to an unexpected increase in demand. ${ }^{221}$ This allows the public to infer that the price increase is associated with inventory produced before the surge, making it unnecessary to cover costs and so a brazen attempt to redistribute at the public's expense. ${ }^{222}$ State price gouging laws generally attack only a small subset of price gouging, because they generally apply only to a narrow set of products classified as necessities, and because they generally apply only during periods when the state has declared an emergency, and states do not always declare an emergency whenever there is a surge in demand. ${ }^{223}$ My per se rule against price gouging, broadly defined, would effectively leverage the antitrust laws greatly to expand the ambit of prohibitions on price gouging, although only with respect to cases in which prices are increased algorithmically. My proposed rule would have meant, for example, that any attempt by Amazon to engage in price gouging with respect to pandemic-related items in the days and weeks immediately following the institution of coronavirus lockdowns in 2020 would have violated the antitrust laws, even with respect to products not typically considered necessities by state price gouging statutes, and even for sales in states that had not declared an

\footnotetext{
218 See BARBara Fried, The Progressive Assault on Laissez FAIRE: Robert Hale AND THE FIRST LAW AND ECONOMICS MOVEMENT 74-75 (1998) (describing "rent-theory Lockeanism as the doctrine that: "Individuals had a moral right only to that portion of income that compensated them for the costs of production; any unearned surplus above that amount was the moral property of the community, which it could appropriate and redistribute as it chose.").

219 See Woodcock, supra note 74, at 53-55.

${ }^{220}$ See id. at 51-53.

${ }^{221}$ See id. at 52.

222 See id.

${ }^{223}$ See id. at 51, 57; Woodcock, The Economics of Shortages, supra note 33.
} 
emergency. ${ }^{224}$ Amazon's surge pricing of hand sanitizer would, for example, have been prohibited, even though many state price gouging laws do not cover cleaning supplies. ${ }^{225}$

\section{B. Beyond Algorithmic Pricing}

1. Toward a Blanket Ban on All Surge Pricing, Including Non-Algorithmic Surge Pricing

The requirement in my proposed rule that price be increased algorithmically contributes nothing to the case for the consumer harmfulness of surge pricing. It is required only to bring surge pricing within the ambit of the antitrust laws by establishing that the defendant took affirmative steps to increase the speed with which prices change, and therefore the speed with which the effects of pre-surge competition on prices are dissipated. ${ }^{226}$. The remaining requirements, that the firm (2) experience a surge in demand and (3) increase its prices in response to that surge (4) faster than the firm increases its supply are sufficient to establish consumer harm, as shown in Section II.B. It follows that applying the test without the requirement that the firm raise prices algorithmically defines conduct that harms consumers but which does not necessarily violate the antitrust laws.

The universe of this conduct is likely to be quite large because, as noted in Section III.B, unexpected surges in demand are a pervasive part of economic life. ${ }^{227}$ They occur not just in consumer goods, but also, for example, in real estate. ${ }^{228} \mathrm{~A}$ homeowner who puts his house up for sale at one price, only to find that demand is so strong that buyers are willing to bid higher prices, faces an unexpected surge in demand. ${ }^{22}$ If the homeowner in fact accepts the highest bid, rather than simply selling the house to the first comer willing to pay the homeowner's initial listing price, then the homeowner harms consumers, even though the homeowner uses no

\footnotetext{
${ }^{224}$ See Woodcock, supra note 74, at 57; Woodcock, The Economics of Shortages, supra note 33 .

${ }^{225}$ See Data Shows Amazon Raised Prices during Pandemic alongside Sellers Accused of Price Gouging, supra note 57; Indiana Code $§$ 4-6-9.1-2 (2018) (limiting price gouging restrictions to fuel).

${ }^{226}$ See Woodcock, supra note 74, at 53-54.

${ }^{227}$ See Woodcock, The Hidden Shortages of the Market Economy, supra note 33.

${ }^{228}$ See Woodcock, supra note 74, at 56.

${ }^{229}$ See id.
} 
pricing algorithms to bring about this result. ${ }^{230}$ The listing price is the price at which the homeowner was willing to sell, which implies that it was sufficient to cover the homeowner's costs; to accept a higher bid is, therefore, to charge an above-cost price. $^{231}$ Given the pervasiveness of unexpected surges in demand, Congress has good reason to pass legislation making surge pricing, whether implemented algorithmically or not, a standalone offense. Because such an offense would apply to all price increases that outstrip the ability of the firm to increase output in response to a surge in demand, not just those implemented algorithmically, it would create a blanket obligation in firms - and homeowners - to stick to presurge prices whenever they encounter an unexpected surge in demand, at least until they actually offer for sale any additional output that they produce in response to the surge.

Implementation of a general, standalone prohibition on surge pricing, including surge pricing that does not employ algorithms, would be potentially more difficult than implementing a prohibition on algorithmic surge pricing via the antitrust laws, however, because evidence that price has increased in response to an unexpected surge in demand may be difficult to find in cases in which defendants did not use algorithms. ${ }^{232}$ That is, evidence that an algorithm was programmed to increase prices in response to data suggesting a surge in demand would be sufficient for liability under my proposed rule, but such evidence is necessarily lacking where the firm did not use algorithms to identify a demand surge. ${ }^{233}$ In such cases, some other form of documentation of the firm's decision-making process with respect to the increase in price would be required. ${ }^{234}$

\section{Implications for Theories of Securities and Commodities Trading}

Although much securities and commodities trading is already executed using algorithms, with the result that much securities and commodities trading is already covered by my proposed antitrust prohibition on algorithmic surge pricing, as discussed in Section IV.A.1, it is worth

\footnotetext{
${ }^{230}$ See id.

${ }^{231}$ See id.

${ }^{232} C f$. Woodcock, supra note 134, at 331-32 (observing that the use of algorithms to implement personalized pricing makes personalized pricing easy to identify).

233 See EZRACHI \& STUCKE, supra note 46, at 230-32. Of course, determining what an algorithm is programmed to do is not is not always easy. See FRANK PASQUALE, THE Black BoX SOCIETY: THE SECRET Algorithms THAT CONTROL MONEY AND INFORMATION 8-9 (2016).

${ }^{234}$ See EZRACHI \& STUCKE, supra note 46, at 230-32.
} 
considering the implications of a broader ban on all surge pricing, both algorithmic and non-algorithmic, for securities and commodities markets. ${ }^{235}$ Such a ban would amount to a blanket prohibition on speculation. Speculation is, after all, the purchase of a good in the hope that demand will unexpectedly rise, allowing the speculator to sell the good at some markup over cost and thereby to generate a profit. ${ }^{236}$ The hope is that the increase will be unexpected because, if it were expected, then the price of the good should already have adjusted upward to eliminate any profit opportunity. ${ }^{237}$ Speculation is, therefore, no more than the act of entering into a business transaction in the hope of being able to profit from surge pricing, algorithmic or otherwise. It follows that a blanket ban on surge pricing would put an end to speculation, at least in principle.

Understanding that speculation and surge pricing are one and the same makes clear that the common defense of speculation, that it facilitates "price discovery"-meaning that it ensures that the prices of securities or commodities accurately reflect the value placed upon them by buyers-is really just the signaling argument that we considered and rejected in Section III.A. In the context of securities and commodities, the argument is that the man who does nothing more productive than to buy low and sell high, earning a windfall profit that represents a pure redistribution of wealth from buyers to himself, nevertheless does something socially useful by pushing prices up to reflect the maximum value that buyers place on goods. This ensures that sellers know the full value that buyers place on companies and commodities, allowing sellers - at least the original securities issuers and commodities producers - to incur costs in producing them that are consistent with that value. ${ }^{238}$ The critique of signaling in Section III.A makes clear that the defense of speculation is based on false necessity: prices do not actually need to approximate maximum willingness to pay in

\footnotetext{
${ }^{235}$ See Budish et al., supra note 191, at 1548-49.

${ }^{236}$ See Nicholas Kaldor, Speculation and Economic Stability, 7 REV. ECON. STUD. 1, 1 (1939) ("Speculation, for the purposes of this article, may be defined as the purchase [or sale] of goods with a view to re-sale [re-purchase] at a later date, where the motive behind such action is the expectation of a change in the relevant prices relatively to the ruling price and not a gain accruing through their use, or any kind of trans- formation effected in them or their transfer between different markets.").

${ }^{237}$ See id. (stating that "in a world of perfect foresight nobody could make a speculative gain").

${ }_{238}$ See Barry, supra note 214, at 1316-19 ("Under these conditions, securities prices should continuously reflect all available information, leading to greater accuracy in the pricing of individual securities and to a more efficient allocation of resources. When stocks and their prospects for success or failure are evaluated by a process that reflects all available information, investors can more rationally compare competing companies.").
} 
order for issuers or producers to allocate the right amount of resources toward building their firms or producing commodities. ${ }^{239}$ When a trader chooses to allow a security or commodity to sell out at the pre-surge price, the trader actually sends an equally useful signal to the market. ${ }^{240}$ The trader tells the market approximately what cost of production an issuer or producer must have to compete effectively against other issuers or producers in the market. ${ }^{241}$ The firm may not be able to minimize costs to the same extent, but in inducing the firm to strive to minimize them, this cost signal ensures that firms incur costs no higher than necessary to serve the market. ${ }^{242}$

It should be no surprise that there is more than one kind of valuable information to be signaled to the market, because markets contain two different kinds of information: information about demand, represented by the demand curve, and information about supply, represented by the supply curve. ${ }^{243}$ Rationing with price conveys information about demand. ${ }^{244}$ But selling out contains information about supply. ${ }^{245}$ Both kinds of information inform the market's allocative decisions and so both help markets to allocate efficiently. ${ }^{246}$ The only really important difference between the two is that the price signal enriches sellers at the expense of buyers because it gives sellers information about the maximum that buyers are willing to pay, whereas the sell-out signal enriches buyers at the expense of sellers because it gives sellers only information on the level of costs required to compete successfully in the market. ${ }^{247}$ So human intuition was right all along to revile the speculator as engaged in an essentially redistributive project in favor of himself - at least so long as human intuition tends to side with the interests of buyers. ${ }^{248}$

\section{Accounting for Risk}

One loose end in the argument for a blanket ban on all surge pricing,

\footnotetext{
${ }^{239}$ See Woodcock, The Hidden Shortages of the Market Economy, supra note 33.

${ }^{240}$ See id.

${ }^{241}$ See id.

${ }^{242}$ See id.

${ }^{243}$ See id.

${ }^{244}$ See id.

245 See id.

${ }^{246}$ See id.

${ }^{247}$ See supra Section II.B.

${ }^{248}$ See Sebastian Lotz \& Andrea R. Fix, Not All Financial Speculation is Treated Equally: Laypeople's Moral Judgments about Speculative Short Selling, 37 J. ECON. PsYCHOL. 34, 35 (2013).
} 
both algorithmic and non-algorithmic, is the problem of compensation for risk. Firms may need the potential gains from surge pricing to offset the risk of losses associated with their ventures. Surge pricing may therefore be necessary to induce optimal levels of entrepreneurial risk taking. ${ }^{249}$ In the argument for an antitrust rule against algorithmic surge pricing in Section II.C.2, the problem of compensation for risk was resolved by observing that risk-taking and economic growth were healthy in the decades immediately before the advent of surge pricing. It followed that banning algorithmic surge pricing, which provides compensation for risk additional to what was on offer before algorithmic surge pricing became possible, is unlikely to deny firms adequate compensation for risk. This argument cannot, however, be used to support a ban that would include non-algorithmic surge pricing, because non-algorithmic surge pricing existed before the information age. Firms have non-algorithmically exploited the shortages created by unexpected surges in demand since time immemorial. ${ }^{250}$ Non-algorithmic surge pricing was in use during the period of healthy economic growth and risk taking that preceded the advent of algorithmic surge pricing. It may well have contributed to the economic growth and risk taking that flourished during that period. Eliminating it might conceivably reduce growth and risk taking today. ${ }^{251}$

To address this problem, a blanket rule against surge pricing, both algorithmic and non-algorithmic, would really need to be two rules. One would be the blanket ban on algorithmic surge pricing that is the main proposal of this Article. The other would be a rule against non-algorithmic surge pricing that would apply only where the surge in demand was not only unexpected but unforeseen. The distinction between unexpected and unforeseen demand surges is technical but important. A surge in demand that a firm thought was possible, but not likely to happen, is an unexpected surge in demand. ${ }^{252} \mathrm{~A}$ surge in demand that the firm thought was impossible, but happens anyway, is an unforeseen surge in demand. ${ }^{253}$ This distinction is important because surge pricing with respect to unforeseen surges in demand cannot provide an incentive to firms to take risks and so

\footnotetext{
${ }^{249}$ See supra Section II.C.2.

${ }^{250}$ See, e.g., ARISTOTLE, THE POLITICS 1997-98 (Trevor J. Saunders ed., 1981) (recounting that ancient Greek philosopher Thales took advantage of an unexpected surge in demand for olive presses to "let them out at any rate which he pleased, and made a quantity of money").

${ }^{251}$ See FRIED, supra note 218, at 202.

${ }^{252}$ See Stephen F. LeRoy \& Larry D. Singell, Knight on Risk and Uncertainty, 95 J. POL. ECON. 394, 394-95 (1987).

${ }^{253}$ See id.
} 
cannot count as a form of compensation for risk. A firm that thinks a surge in demand to be impossible will not factor the possibility of earning profits from raising prices during such a surge into account in deciding whether to make risky investments. So it is possible to ban surge pricing in the case of unforeseen surges in demand without altering the investment behavior of firms.

In economic parlance, the distinction between unexpected and unforeseen surges is a distinction between risk and uncertainty. ${ }^{254}$ High prices can be necessary to compensate for risk because risk involves known unknowns-possibilities to which a firm can assign nonzero probabilities. $^{255}$ The firm can then use those probabilities to calculate precisely how much profit it will need in some possible states of the world to compensate for losses in other possible states of the world - or to compensate for charging a lower-than-necessary pre-surge price. For example, a firm that believes that there is a $10 \%$ chance that demand will disappoint, leading to a $\$ 100$ shortfall, but also a $5 \%$ chance that demand will surge, allowing the firm to generate $\$ 200$ in surge pricing profits, can calculate that the probability-adjusted gains from surge pricing as $10 \%$ of $\$ 100$, or $\$ 10$, which is equal to the probability adjusted loss of 5\% of $\$ 200$. If there is an $80 \%$ chance that demand will be as expected, and the presurge price is set to cover costs, then if the firm surge prices it will on average break even. The profits from surge pricing during the possible demand surge will fully compensate for the losses during the possible demand shortfall.

By contrast, high prices are never necessary to compensate for uncertainty because uncertainty involves unknown unknowns - states of the world that cannot be imagined, let alone assigned a numeric probability. ${ }^{256}$ Firms cannot assign probabilities to states of the world that they believe do not exist, and so they cannot calculate the profits they would need to generate in those states in order to break even. If a firm does not know that there is a 5\% chance of a surge in demand that will yield $\$ 200$ in profits through surge pricing, the firm will not plan on using those $\$ 200$ to offset losses in other possible states of the world. The firm will either not undertake the project or find some other way of compensating for the risk of losses, such as generating more profits up front by charging higher presurge prices if pre-surge competition allows.

The distinction between unexpected and unforeseen surges does for the

\footnotetext{
${ }^{254}$ See id.

${ }^{255}$ See id.

${ }^{256}$ See id.
} 
argument that surge pricing is not necessary to cover the risk of losses what the distinction between expected and unexpected increases in demand does for the basic argument, developed throughout this Article, that surge pricing is not necessary to cover production costs. The heart of that basic argument is that firms do not use profits generated from surge pricing to cover costs because firms do not expect demand to surge. They expect that pre-surge prices will persist and so they choose their pre-surge prices to cover costs. Any additional revenues generated through surge pricing therefore represents profits in the economic sense of a redistribution of surplus from consumers. The heart of the argument that surge pricing is not needed to compensate for the risk of losses is that firms do not use profits generated from surge pricing in unforeseen states of the world to offset the risk of losses because firms assign a zero probability to unforeseen states of the world. They choose their prices in the states of the world to which they assign non-zero probabilities to cover their costs. Any additional revenues generated through surge pricing in unforeseen states of the world therefore represents profits in the economic sense of a redistribution of surplus from consumers.

This solution to the problem of compensation for risk is complete as a matter of theory. But implementing a blanket ban on all surge pricing, both algorithmic and non-algorithmic, on the basis of this argument would be harder than implementing a ban on algorithmic surge pricing alone. That is because proving that demand reached unexpected levels, as required to implement a ban on algorithmic surge pricing alone, only requires information regarding the demand level expected by the firm's pricing algorithm. By contrast, proving that demand reached unforeseen levels, as required to extend a ban to non-algorithmic surge pricing, requires information regarding the set of levels of demand that the firm thought impossible. Only practitioners of non-algorithmic surge pricing that engage in a systematic consideration of possible states of the world are likely to leave a paper trail regarding states of the world that they believe to be impossible. And because non-algorithmic surge pricing does not, of course, use algorithms, finding that paper trial would in fact involve rummaging through paper, or at least consulting electronic information that is not directly integrated into the firm's pricing processes and so may be easier for firms to hide. Difficulty of enforcement is not, however, an argument against extending a ban to non-algorithmic surge pricing. Liberal construal of a ban, such as by treating proof that a firm never considered the possibility that demand might reach a certain level as equivalent to proof that the firm thought that level of demand to be impossible, could help give it more bite. 


\section{Beyond Unexpected Increases in Demand}

Algorithmic surge pricing harms consumers because an unexpected surge in demand creates a temporary industry-wide shortage at pre-surge, cost-covering prices and surge pricing exploits that shortage to raise prices to consumers above costs. ${ }^{257}$ (In the algorithmic surge pricing context addressed in this Section, the risk compensation argument can be ignored for the reasons given in Section II.D.) In addition to such temporary shortages, economies also suffer permanent or near-permanent shortages because some natural resources, such as land, air, ${ }^{258}$ water, minerals, and the like are permanently fixed in supply. So long as they are not improved, they have a production cost of zero, which means that demand very often exceeds supply at the zero price necessary to cover their cost of production, as shown in Figure 15. ${ }^{259}$

\footnotetext{
257 See supra Section II.B.

${ }^{258}$ It would be a mistake to suppose that air is not scarce. It is scarce, as anyone who has been stifled in a crowd can attest. Air is not, however, owned (or in need of being produced), which is why it appears plentiful to us. Indeed, it is only because air is, ultimately, both scarce and incredibly valuable that the state does not grant property rights in it. For the irreproducibility of the atmosphere and the great value consumers place on it - they cannot survive without air-means that the ration price that would be charged would be so high as to beggar everyone but air's owners. Access to air is as essential to life as access to personal safety-the monopolization of which is the source of all governmental power-and so any government that was foolish enough to grant property rights in air would need quickly to dissolve them; to do otherwise would be to create an institution that would rival its own power. See Ramsi A. Woodcock, The Contrasting Approaches to Power of the Modern State and the Antitrust Laws: Lessons for Platform Regulation, SSRN (2020), https://papers.ssrn.com/sol3/papers.cfm?abstract_id=3704450.

${ }^{259}$ See FRIED, supra note 218, at 91-92, 122 (describing land as "nature's bounty").
} 


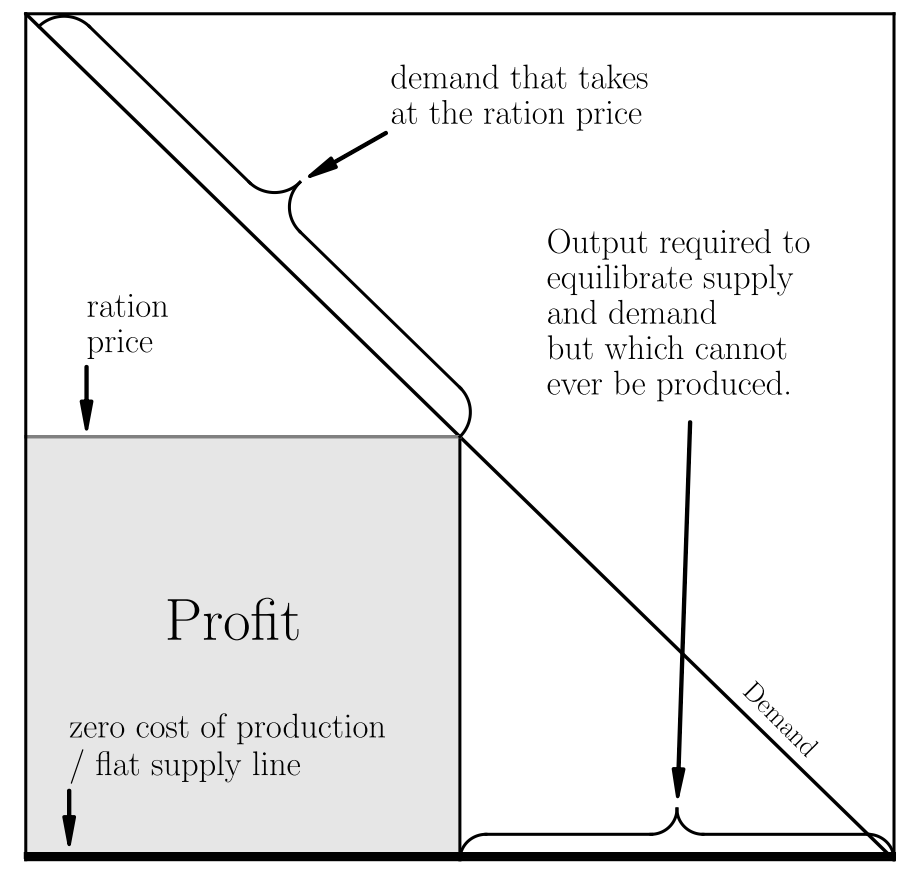

Figure 15

When owners of these resources charge a price - any price above zero-for them, they engage in the equivalent of surge pricing in the sense that they use price to ration access to the scarce resource, and thereby extract economic profits from consumers. ${ }^{260}$ All of the arguments set forth in Part II and Part III for the superiority, from the perspective of consumers, of selling out relative to surge pricing, apply in the context of permanent resource shortages. Because the cost of producing unimproved resources is zero, owners can be made to give them away for free without reducing supply, and consumers would, of course, be made better off. Those arguments also provide a full response to any attempt to justify the sale of unimproved land as a means of allocating it to those who value the land the most. ${ }^{261}$ Those who value the land the most are just as likely to get in line

\footnotetext{
${ }^{260}$ See id. at 122 (describing the rent of land as "a return for nature's bounty rather than human effort').

${ }^{261} C f$. Mankiw, supra note 38 ("It was only because the price was so high that I was able to buy tickets at all on such short notice. If legal restrictions or moral sanctions had forced prices to remain close to face value, it is likely that no tickets would have been available by the time my family got around to planning its trip to the city.").
} 
first to obtain it as they are to be able to win the bidding for it. ${ }^{262}$ Moreover, concerns about the need to use high prices to compensate for risk do not apply to unimproved natural resources, because an owner who invests nothing in the improvement of a resource (and so has no cost of production) cannot need compensation for risk. ${ }^{263}$ The owner risks nothing; if the good is destroyed, the owner's loss is zero.

There can be no antitrust liability for selling unimproved resources, however, because the permanence of the shortage of scarce natural resources makes it impossible to posit the existence of an earlier period of relatively competitive pricing that the firm takes affirmative steps to cut short through the charging of high (or, in this case, any nonzero) prices. ${ }^{264}$ A scarce natural resource generally has always been in short supply-in the sense that demand always has outstripped supply at a zero price-and so, presumably, the resource's owners always have sought to exploit the shortage by charging for access to it. Thus the anticompetitive conduct that serves as the predicate for an antitrust claim against surge pricing-the hastening of the demise of pre-surge competitive pricing-does not exist in the case of natural resources in permanent shortage. ${ }^{265}$ But Congress may nevertheless wish to intervene to prevent the resulting consumer harm by passing new legislation prohibiting the sale-as opposed to gifting-of scarce and unimproved natural resources.

One apparent obstacle to banning the sale of unimproved resources is that an unimproved resource appears to have no cost of production only when the owner receives the resource as a grant from the state, or as an inheritance or bequest. When the resource is acquired through purchase it appears, by contrast, to have a cost, equal to the purchase price. ${ }^{266}$ This argument is not, however, correct. ${ }^{267}$ The purchaser of an unimproved resource - say, unimproved land — does pay a price for the land, and so may appear to incur a cost, but that cost is an illusion. ${ }^{268}$ It represents no more

\footnotetext{
262 See supra Section III.C.

${ }^{263}$ See supra Section IV.B.3.

${ }^{264}$ See supra Section II.C.1.

265 See supra Section II.C.1.

266 See FRIED, supra note 218, at 197-98.

267 See id. at 120 n. 69.

268 See id. One scarce natural resource for which the illusion that the purchase price is a cost does not arise is raw human talent. Talent cannot be bought and sold, and so it is always clear that its possessor acquired it at zero cost. Because talent cannot be sold, a ban on the sale of scarce, unimproved resources would not apply to it. To be sure, people often sell the fruits of their talent. But those fruits have a production cost in terms of time, training, or what have you.
} 
than a division of the proceeds of above-cost pricing between owners across time. The first acquirer of the land sells it at a non-zero, and therefore above-cost, price, redistributing wealth from the buyer to himself. The buyer is, then, the victim of the surge pricing of the first acquirer. But, when the buyer sells, again charging a price for the unimproved resource, the buyer, who is now a seller, victimizes a new buyer, possibly to a greater extent if demand for the land has increased. The price paid by the second buyer is not attributable to the cost of productive activity of any kind by the first buyer, but rather to pure redistribution of wealth. It represents a debiting of the second buyer's bank account and a crediting of the first buyer's bank account, and nothing more. To prevent the second buyer from charging a nonzero price in turn in reselling the property to a third buyer is not, therefore to prevent him from charging a price necessary to cover his real costs of production, for these do not exist. It is simply to prevent him from recouping the wealth that was taken from him by in turn taking wealth from a third buyer. Preventing those who have purchased unimproved land from selling it would impoverish buyers who were, themselves, victims of the original or subsequent buyers. ${ }^{269}$ The solution to that problem is not to continue the chain of victimization ad infinitum, but either to find the original seller and make him disgorge his gains to the current owner who is forced to give the property away, or to apportion the loss equitably among as many subsequent buyers as remain alive, by having each living seller disgorge some of his proceeds of sale to the current owner. ${ }^{270}$

Congress could not, however, proceed by imposing a direct ban on the sale of scarce, unimproved resources. The trouble is that owners can evade such a ban by making slight improvements to their scarce resources. The landowner puts up a fence. The improvement, no matter how slight,

269 See id. at 201 ("Hale and others were reluctant to attack windfall gains to past investments, recognizing that investors may have purchased such investments at a price that reflected the possibility of inframarginal rents.").

${ }^{270} C f$. id. Allowing the chain of victimization to continue ad infinitum would, somewhat paradoxically, eliminate any identifiable victim, since it is only when the chain of sale stops getting longer that someone is left holding the loss. Given that at some point civilization will come to an end, this argument is unsatisfying. See generally PETER D Ward \& Don Brownlee, The LifE and Death of Planet EARTh: How the NeW Science of ASTROBiology Charts the Ultimate FATE OF OUR World (2004). There will, ultimately, be a victim, and the longer the chain of sale, the larger the circle that is implicated in the offense.

It would be preferable to make the estate of the original owner disgorge the original owner's gains to the current owner who is forced to give the property away, but in practice those gains may already have been dissipated by the estate. Hence the need to apportion the loss equitably among living former owners. 
associates provision of the resource with a cost, and once that is done a blanket ban on sale of the resource at any non-zero price is no longer justified. ${ }^{271}$ Now some amount of payment for the resource is necessary to cover costs, and so it becomes efficient only to prohibit the charging of a price for the resource above its cost, rather than to prohibit the charging of any non-zero price at all. ${ }^{272}$ The only way effectively to prohibit the charging of a non-zero price for an unimproved resource is both to prohibit the charging of a non-zero price for the resource and to regulate the prices that firms charge for improved resources to ensure that prices are no higher than necessary to cover costs. Only the combination of a ban on the sale of unimproved resources and price regulation for improved resources can make a firm in possession of an unimproved resource actually give it away. Only then is selling it in unimproved form impossible and selling it after making small improvements to sidestep the ban on sale of unimproved resources unprofitable as well, and so no way around the ban.

Governments regulate prices either directly through rate regulation or indirectly through corporate taxation. In the case of rate regulation, an administrative agency determines a firm's costs and imposes a price high enough only to cover costs. In the case of corporate taxation, tax authorities force firms to pay out a share of their revenues that, after deductions are taken into account, approximates the economic profits firms earn from above-cost pricing. ${ }^{273}$ Any serious attempt to ban the charging of a non-zero price for the sale of an unimproved resource would need to be accompanied by significant strengthening of contemporary rate regulation or corporate taxation regimes, because rate regulation today exists only in a select few industries, and corporate tax rates today are likely too low fully to tax away any firm's economic profits. ${ }^{274}$ But even a greatly strengthened regime of rate regulation or corporate taxation would fall short of denying firms all economic profits from the sale of unimproved resources. Both rate

\footnotetext{
${ }^{271}$ See FRIED, supra note 218, at 123; S.H. Patterson, The Ralston-Nolan Bill: A Proposed Tax on Unimproved Land Values, 95 AnNAls AM. ACAD. Pol. \& Soc. ScI. 188, 189 (1921) ("Improvements upon land are of such a permanent nature that they tend to become part of the land. Witness the labor expended in clearing or draining a piece of land for farming. Shall we say that a stream is a natural resource but that an irrigation ditch of the same size is capital? How can fertilizer be classified? The practical difficulties of differentiating between land itself and the improvements upon it are very great.").

272 See FRIED, supra note 218, at 123.

273 See VISCUSI ET AL., supra note 97, at 539-57; Reuven Avi-Yonah, A New Corporate Tax, TAX Notes FEDERAL 653, 655-57 (2020).

274 See Joseph D. Kearney \& Thomas W. Merrill, The Great Transformation of Regulated Industries Law, 98 CoLUM. L. REV. 1323, 1335-40 (1998); Avi-Yonah, supra note 273, at 658.
} 
regulation and taxation are, even at their best, approximate. Even under either regime at its best, owners would likely still be able to extract some profits from consumers on the sale of unimproved resources through the application of de minimis improvements. ${ }^{275}$ The charging of a price for unimproved resources would, therefore, continue, albeit with reduced harm to consumers, thanks to the approximate action of rate regulation or taxation against profits earned on the sale of resources with de minimis improvements.

Another approach to banning the charging of a non-zero price for an unimproved resource would be simply to eliminate all property rights in unimproved resources. If a thing cannot be owned then it cannot be sold; it can only be given away, presumably to the first comer. This amounts to selling out of the resource at a price equal to its production cost of zero, which is precisely what a ban on sale at a non-zero price is meant to achieve. One problem with this approach is that, like a ban on sale at a nonzero price, owners could make an end run around the ban by making de minimis improvements to the resource, which would then give them a right of ownership. ${ }^{276}$ So this approach, too, would need to be accompanied by price regulation for improved resources. A deeper problem with this approach is that society might have an interest in both maintaining some property rights over unimproved resources, such as the right to exclude, and in prohibiting the charging of a price for unimproved resources at the same time. ${ }^{277}$ Society might want an owner of the forest primeval to be able to prevent loggers from coming onto the land to strip it, but at the same time not want that owner to be able to dispose of the land through sale as opposed to giving it away to the first person who answers a call to transfer title. ${ }^{278}$ Property rights do discourage waste. The case against charging a price for unimproved resources is not a case against property rights per se, only a case against charging a non-zero price for their transfer.

\footnotetext{
275 See VISCUSI ET AL., supra note 97, at 559-537; FRIED, supra note 218, at 203.

276 Although there is no general principle of property law that grants ownership over resources to their improver, improvement often does tend to lead to property rights, either de jure or de facto. Those who manufacture oxygen by separating it out of air they do not own do not, one might suppose, own the oxygen either. But it is doubtful that a court would dismiss a claim for conversion of oxygen canisters on the ground that the oxygen, as a derivative of unowned air, cannot itself be owned. Even if a court were to conclude that oxygen cannot be owned, the court would likely recognize a claim for conversion of the physical canisters themselves, as opposed to the oxygen in them, which as a practical matter, amounts to the same thing.

277 See Garrett Hardin, The Tragedy of the Commons, 162 SCI. 1243, 1245 (1968).

${ }^{278}$ See id.
} 
The need to resort to price regulation in order to make either a direct ban on the sale of unimproved resources or a denial of all property rights in unimproved resources effective contrasts with the simplicity of a ban on surge pricing, which, as we have seen, can be executed without the aid of price regulation. In the surge pricing context, firms cannot muddy the waters by adding de minimis improvements to their products because when they engage in surge pricing firms raise their prices faster than they can increase - or improve - their output. ${ }^{279}$ Thus banning price increases in that context never risks denying firms the ability to cover their costs. That makes it unnecessary to use rate regulation or taxation to identify a firm's costs and ensure that prices meet them.

\section{CONCLUSION}

Surge pricing is the exploitation of lapses in the beats of industrial hearts that are too well loved by consumers. Not just love is required, but the coup de foudre. Then firms find themselves facing a demand for which neither the firms nor anyone else has prepared, and, in consequence, firms find themselves facing scarcity-that root of all power, economic and otherwise. Firms that create scarcity can violate the antitrust laws. But scarcity born of sudden ardor does not violate them, for who can create a clap of lightning? Power acquired by chance may legally be exploited; the firm can raise prices during that lapse in the beat of the industrial heart, while competitors and the firm itself float, suspended in freeze-frame, about to bring the defibrillator of production back down on the market but unable yet to do so. During this pause, the firm can ration access to its good by raising prices. That is, the firm can increase prices until the good is no longer in danger of selling out, despite the surge in demand, because some of those who would have been willing to buy at the pre-surge price are driven from the market by the high price. In raising prices, the firm raises its revenues above its costs, for inventories have not had time to expand, and the pre-surge price would have been chosen to cover the cost of existing inventories.

But the firm's entitlement to exploit its admirers should be limited. The firm should not be permitted to heighten its powers of exploitation by adopting technologies that increase the speed with which the firm can raise prices. To do that is anticompetitive in the sense that it hastens the dissipation of the effects of any competition that predated the surge in demand, which effects are otherwise felt in the form of the persistence of

\footnotetext{
${ }^{279}$ See supra Section II.B.
} 
the firm's charging of the presumptively competitive pre-surge price over the course of the surge. By the same token, antitrust does not prohibit tacit collusion, which can give a group of firms power over price but little ability actually to target a particular higher price, but antitrust does prohibit price fixing, which dissipates the effects of any competition that existed before the collusion commenced by allowing the colluders actually to agree upon and impose a particular higher price. Thus the antitrust limit to surge pricing must be algorithms. It must be that while firms can ration the lapses of production with price all they want, they cannot use algorithms to do it faster.

Perhaps because surge pricing is ultimately exploitation-it is the charging of prices that are above costs and so not necessary to induce production - all of surge pricing's defenses are defenses of exploitation writ large. One such defense is that high prices charged during a shortage signal to competitors that there are profits to be made by entering the market to end the shortage. This argument can be deployed in defense of all attempts to use price to ration access to a good in short supply, not just the particular form that is surge pricing. The fault in this defense is that the alternative to rationing with price, which is to let the good sell out at a price that just covers costs (the pre-surge price in the surge pricing context), is just as good at signaling. The sell-out signal tells competitors that there are profits to be made by entering the market to sell at a price that is slightly higher than the low price that covers costs (i.e., the pre-surge price in the surge pricing context), just as rationing with price tells competitors that there are profits to be made by entering the market to sell at a price that is slightly lower than the high ration price (i.e., lower that the surge price in the surge pricing context). The sell-out signal has the advantage of bringing the lowest cost production into the market first. The ration pricing signal has the advantage of potentially appealing to more competitors with a wider variety of cost profiles. It is unclear which of the two is better for consumers, and so signaling provides no basis for preferring ration pricing — or, indeed, surge pricing — to selling out.

The other major defense is that high, surge prices allocate scarce goods to those who value them the most. This argument, too, can be deployed in defense of all attempts to use price to ration access to goods in short supply, not just the particular form that is surge pricing. And the trouble with the argument, here again, is that the alternative of selling out does the same. Rationing with price allocates based on willingness to pay, which is an imperfect proxy for value because the rich are willing to pay more for things like food that they value no more than the rest of us. Selling out allocates based on the principle of antecedence, which is also an imperfect proxy for value because those who place the highest value on a good are not 
always able to claim it first. The important thing is that it is not clear which proxy is worse, with the result that allocation provides no basis for preferring ration pricing - or, indeed, surge pricing - to selling out. Indeed, from an allocative perspective rationing with price and selling out seem to shade into each other, with plutocrats buying their way to the head of lines and early birds lining up first to become plutocrats.

The generality of these two defenses-signaling and allocative efficiency are both used to justify an astonishing range of economic activity, from stock market speculation to the enclosure and sale of virgin land-tells us something about the generality of the critique of surge pricing. Because, at its heart, surge pricing is no more than the exploitation of scarcity, the critique of surge pricing is really a critique of all exploitation of scarcity and provides a basis for condemning it all. The difference between surge pricing and other forms of exploitation of scarcity, however, is that the remedy for surge pricing - to ban the practice - is not available more generally, for it is usually unclear what part of the price charged for a scarce good is due to scarcity and what part is required to cover costs. As a result, only rate regulation and taxation can remedy exploitative pricing as a general matter, for only those regimes attempt to determine costs and eliminate revenues in excess thereof.

Surge pricing is different because the unexpectedness of the surge catches firms off guard. They have already set their prices to cover the costs of their existing inventory and have no plan to produce more in the short run. When they raise prices during the surge-before they have time to incur additional costs by increasing output - they therefore necessarily raise their prices above their costs, and so the law can be confident that in banning surge pricing it will have no effect on economic behavior.

But it will change the distribution of wealth. 